This is an electronic reprint of the original article. This reprint may differ from the original in pagination and typographic detail.

Author(s): Isomöttönen, Ville; Tirronen, Ville

Title: $\quad$ Flipping and Blending : An Action Research Project on Improving a Functional Programming Course

Year: $\quad 2016$

Version:

Please cite the original version:

Isomöttönen, V., \& Tirronen, V. (2016). Flipping and Blending : An Action Research Project on Improving a Functional Programming Course. ACM Transactions on Computing Education, 17(1), 1:1-1:35. https://doi.org/10.1145/2934697

All material supplied via JYX is protected by copyright and other intellectual property rights, and duplication or sale of all or part of any of the repository collections is not permitted, except that material may be duplicated by you for your research use or educational purposes in electronic or print form. You must obtain permission for any other use. Electronic or print copies may not be offered, whether for sale or otherwise to anyone who is not an authorised user. 


\title{
Flipping and Blending-An Action Research Project on Improving Functional Programming Course
}

\author{
VILLE ISOMÖTTÖNEN and VILLE TIRRONEN, University of Jyväskylä
}

\begin{abstract}
This article reports on an action research project on improving a functional programming course by moving towards a practical and flexible study environment-flipped and blended classroom. Teaching the topic of functional programming was found to be troublesome using a traditional lectured course format. The need to increase students' amount of practice emerged, while subsequently challenges relating to students' independent practical coursework were observed. Particular concerns relating to group work, learning materials, and the attribute of flexibility were investigated during the third action research cycle. The research cycle was analyzed using a qualitative survey on students' views, teacher narrative, and students' study activity data. By this third research cycle, we have found that (1) the 'call for explanation' is an apt conceptualization for supporting independent work, and in particular for the design of learning materials, (2) use of studentselected groups that can be flexibly resized or even disbanded enables spontaneous peer support and can avoid frustration about group work, and (3) students greatly appreciate the high degree of flexibility in the course arrangements but find that it causes them to slip from their goals. The project has improved our understanding of a successful implementation of the target course based on group work and learning materials in the context of independent study, while the attribute of flexibility revealed a contradiction that indicates the need for further action.
\end{abstract}

CCS Concepts: $\bullet$ Social and professional topics $\rightarrow$ Computer science education;

Additional Key Words and Phrases: Action research, flipped classroom, blended learning, independent study, functional programming

ACM Reference Format:

Ville Isomöttönen and Ville Tirronen, 2016. Flipping and Blending-An Action Research Project on Improving Functional Programming Course. ACM Trans. Comput. Educ. V, N, Article X ( 2016), 36 pages.

DOI : 0000001.0000001

\section{INTRODUCTION}

Functional programming is considered to be challenging by first timers as effective functional programming requires learning of several difficult abstractions and topics such as the modern type system of these languages [Clack and Myers 1995; Chakravarty and Keller 2004]. From a curricular perspective, students are often required to move from imperative languages to a functional one and difficulties arise when imperative thinking is applied within the functional domain [Joosten et al. 1993; Clack and Myers 1995]. Closely related to the research reported in the present article, we have come to know of student challenges with syntax and types when using Haskell functional language [Tirronen and Isomöttönen 2015; Tirronen et al. 2015].

This article reports on an action research project, which arose out of experiencing wastage of time and effort in teaching functional programming. We postulated that students could practice basic concepts independently, and that helping students grasp

Authors' addresses: Department of Mathematical Information Technology, P.O.Box(35), 40014-FIN, University of Jyväskylä, Finland. Email: \{ville.isomottonen,ville.tirronen\}@jyu.fi.

Permission to make digital or hard copies of all or part of this work for personal or classroom use is granted without fee provided that copies are not made or distributed for profit or commercial advantage and that copies bear this notice and the full citation on the first page. Copyrights for components of this work owned by others than the author(s) must be honored. Abstracting with credit is permitted. To copy otherwise, or republish, to post on servers or to redistribute to lists, requires prior specific permission and/or a fee. Request permissions from permissions@acm.org.

(C) 2016 Copyright held by the owner/author(s). Publication rights licensed to ACM. 1946-6226/2016/-ARTX $\$ 15.00$

DOI : 0000001.0000001 
the most difficult topics of functional programming would require more practice. We adopted a course model departing from a traditional lectured course format, and developed it further through action. This course model required self-directed learning skills and active participation on the part of the students. Through several course iterations, we studied which course configurations could facilitate students' independent practical coursework. Instead of attempting to directly evaluate learning, we were interested in how students responded to the setting provided-what are the main obstacles and can we remove them?

The focus of this article is our recent action research cycle that seeks to answer to the concerns raised by the first research cycle (see [Isomöttönen and Tirronen 2013]). These particular concerns were how to benefit from group work, how to support individual learning processes, and how to facilitate students' synthesis-making under the conditions of independent study. As the recent changes to the course include features of online courses, we argue that the results shed light on what kind of mixture of classroom and online teaching could be a workable solution for a programming course, and thereby on the promises and challenges posed by online learning environments.

An additional motivation came from the fact that action research methodology is still rather rarely deployed in engineering education research. Quite recently, Case and Light [2011] described it favorably as an 'emerging' methodology in this field and stated that "we need to understand in more depth what actually takes place in real engineering classrooms, particularly when we are implementing innovative pedagogies."

\section{CONTEXTUALIZATION}

\subsection{Target course}

The functional programming course under study is an elective course, which is taken after introductory programming courses: CS1 with C\# and CS2 with Java. This means that students face a transition from imperative to functional thinking ${ }^{1}$. The course is taught using Haskell. The course can be said to be targeted at third- and fourth-year students, while, due to flexibility in our system, many students choose to take it already during the second year and some later than the fourth year. All students plan and follow their personal study plan, and hence this kind of variation is usual and does not concern only elective courses. When we started this research project, we typically had roughly $10 \%$ physics students, $10 \%$ IS students, a few maths students, and the remaining majority were CS majors. This characterization also applies to the 2013 data used in the present study (the third action research iteration). The course was previously defined as a 6-credit master's level course, but now defined as a bachelorlevel course. This change owes to the research project itself. When transforming the course into a flexible environment, exercises were repackaged into clusters matching different amounts of credits. By this change, students can choose to study from (only) one to five credits, and hence the course was confirmed to be a bachelor course. The present action research iteration concerns this change and the course included in the bachelor studies. At the bachelor level, students study mandatory core courses such as Operating systems and Algorithms. Functional programming is one option for five credits of advanced programming needed for the bachelor degree by CS majors. The course is thus not merely a 'voluntary addition' in the curriculum. Other alternatives to advanced programming for CS majors are Web programming, Graphical user interface programming, and Basic of computer graphics, which are, similar to functional programming, taxing to students (as programming courses tend to be in general).

\footnotetext{
${ }^{1}$ Object-oriented languages can be regarded as examples of the imperative style [Harper 2012; Moseley and
} Marks 2006]. 


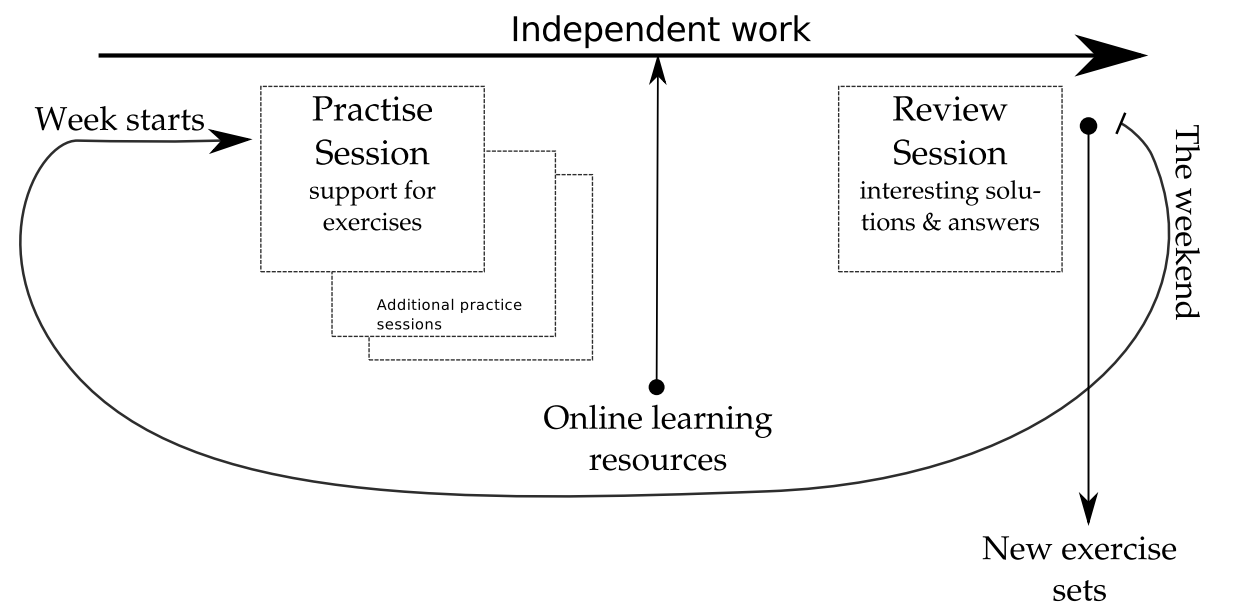

Fig. 1. The basic design of the course

Figure 1 describes the basis of the first action research design of the target course implemented during autumn 2011. The course was implemented in weekly cycles and within a typical academic period. There were no traditional lectures nor exams, and grading was pass/fail-the decisions being made to promote a learning mode and genuine interest in learning the topic [Ryan and Deci 2000]. Most of the students' time was expected to be spent on programming through independent study, while weekly contact sessions were also provided. Students could arrive at support sessions and advance the exercises of the course with support available, and at the end of each week a review session was held, with a focus on emergent challenges and viable solutions. The number of weekly support sessions varied according to the needs of the students. Reading topics and exercises were announced in weekly sets at the end of each week of the course. Learning materials consisted of web resources, specifically particular relevant e-books. Students passed the course by completing the given sets of exercises. Students worked in groups in order to promote peer support among students with the difficult topic, and potentially to benefit from self-directed learners increasing self-direction among their group members.

As mentioned above, the practice-oriented course in Figure 1 was furthered into a flexible delivery studied in this article. The reader is asked to see the beginning of Section 4 for the progression of the research project and Section 4.1 for the changes. The number of students participating (showing any submission activity during the semester) during the present third iteration was 92 , which is roughly twice the number of students during the first course iteration in our research project. Increasing online learning possibilities and allowing students to take the course in different sizes seemed to result in more students at least trying, while we cannot currently claim this as a permanent state or a trend. Students' study activity under a flexible learning condition is dissected in Section 5.5 where we exploratively look at students' exercise submission activity and hence what resulted from a flexible condition.

\subsection{Related educational concepts}

The educational concepts and trends reviewed below contextualize our action research project, allowing the reader to locate the present study within relevant educationalcultural thinking and phenomena. We have not undertaken a study on any of the concepts in order to test or advance theory, but aimed to improve practice based on the 
initial practical concerns in teaching and subsequent issues emerging through taking action. Along with this process, many of the concepts reviewed in the following have informed but not constrained [Case and Light 2011, p. 197] our research.

2.2.1. Independent study. The target course incorporates an element of 'independent study' [Cuthbert 2001], which emphasizes student autonomy and self-directed skills, and calls for the development of generic skills that enable students to tackle authentic assignments. Cuthbert notes that students thereby genuinely take responsibility for their learning. Earlier, Moore [1973] described independent study through the concepts of "autonomous learner" and "distance teaching." The autonomous learner is active, rather than reactive. Such a learner makes plans for learning, actively seeks help, enjoys discussions about the topic, and evaluates learning outcomes as a means of directing and managing his or her learning process. The autonomous learner reaches a state of responsibility where the capacity for learning is exercised without being constrained by such feelings as shame and doubt. Distance teaching relies on media in learning, such that teacher presence is indirect, e.g., through the design of learning materials.

2.2.2. Self-direction, self-determination, self-regulation. Self-direction, -regulation, and -determination characterize the expectations that the present course design and its evolution has imposed on students. Clearly, the biggest challenge we report in the present article relates to expectations of these kinds. These concepts overlap one another and arguably relate to the concept of independent study. Candy [1991] outlines self-direction as an ability to make decisions and critical evaluation independently within a particular domain of knowledge, and is accompanied by learner autonomy and learner control. Self-determination, as described by Ryan and Deci [2000], again alludes to intrinsic motivation for learning and the attribute of well-being, entailing a self-determined condition of learning. Self-regulation, whose definitions vary in the literature, signifies management of one's own learning. It is usually linked with meta-cognition [Flavell 1976], with the learner engaging in the functions such as selfobservation, self-judgment, and self-reaction [Bandura 1986].

Self-direction and self-regulation are regarded as developmental processes [Loyens et al. 2008]. Accordingly, self-direction may require orientating [Taylor and Burgess 1995] and take time to mature [van den Hurk et al. 1999]. As posited by Grow [1991], a learner may also demonstrate high self-direction in a particular subject, while depending on expert support in another. Grow also notes that the way in which a learner responds to a particular teaching situation may depend on the extent to which the teaching style matches the learner's degree of self-direction. As for self-regulation, research has shown that improved study strategies and learning can follow from training; see research reviewed by Zimmerman [2008].

Finally, it should be noted that, while adults are typically assumed to be self-directed learners (e.g., Knowles), many scholars have questioned this assumption, pointing out, for example, that the ability for self-direction may be constrained by the learner's schooling background (see discussion by Henning [2012]).

Our reference to self-directed learning should not be interpreted to mean that we are simply delivering minimally guided instruction. Instead, we find that theories such as cognitive load theory [Sweller et al. 1998] can inform the design of the learning environment where students are expected to perform independent study. We have clearly relied on this theory's ideas of effectiveness in our action research project, which emphasized independent study and learning by doing as a central component of the course [Tirronen and Isomöttönen 2012; Isomöttönen and Tirronen 2013; Tirronen and Isomöttönen 2015]. 
2.2.3. Blended learning. Blended learning refers to scenarios where traditional in-place education is blended with elements of online learning [Osguthorpe and Graham 2003]. In the present study, practical coursework with a difficult course topic foregrounded the challenge created by individual differences and scheduling and the related need to provide the course in a more flexible format, which may be seen as blended learning. The course now comprises self-contained online materials with embedded quizzes and automatic assessment tools, and provides students with the possibility to program directly in the browser environment. This new format meets the goals of blending, that is, increased 'pedagogic richness,' 'personal agency,' and 'access to content' [Osguthorpe and Graham 2003]. It must be noted, however, that, beyond conducting a study on blended learning pedagogy, our quest for efficient online learning in conjunction with contact sessions has been about offering alternatives, in order to make learning of functional programming efficient and taking account of individual differences in the pace of learning.

2.2.4. Flipped classroom. A recent pedagogy placing students in active roles is that of the flipped classroom, a kind of a form of blended learning. Information needed for learning is acquired outside class hours, whereas class time is used for activities intended to support learning. Typically, this means students watching videoed lectures at home and doing assignments during class time with support available. One origin for flipped pedagogy could be seen in the work by Mazur (see [Crouch and Mazur 2001]), who began to devote class time on peer activities; since then, the number of studies on flipped classroom has been increasing. Generally, scholars report positive experiences regarding factors such as student motivation, engagement, and student and teacher satisfaction [Gannod et al. 2008; Amresh et al. 2013; Bijlani et al. 2013; Furse 2013; Lucke et al. 2013], and improved learning outcomes have also been observed [Amresh et al. 2013].

Nevertheless, challenges are also reported. Some students prefer traditional lectures [Gannod et al. 2008], and it is not clear that students will properly prepare for contact teaching sessions by watching videoed lectures [Gannod et al. 2008; Amresh et al. 2013]. Further, the learning outcomes of flipped pedagogy require more empirical research, as may be concluded from the course implementation by Gehringer and Peddycord, III [2013], where improved performance was not observed. Students may also experience time-constrained practical coursework with the element of self-study (learning by doing) as intimidating and overwhelming [Amresh et al. 2013]. From this premise, it is unsurprising that the question of how to devise students' self-study has received considerable attention. Biljani, Chatterjee, and Anand [2013], for example, used concept maps to direct student self-study and help teachers assess the areas of learning requiring support. Lucke, Keyssner, and Dunn [2013] complemented flipped pedagogy with a classroom response system, and reported on the positive student responses regarding this method's usefulness for learning. In summary, response to the flipped classroom appears to be predominantly positive, although, given the experiential and initial nature of many of the studies, more research is needed into student learning processes, successful learning environments, and learning outcomes.

These references accord with the present research aim of deploying student and teacher resources efficiently in the context of the challenge of learning to program. Although our thinking was originally more informed by notions of self-direction and self-determination, the course format we have used resembles the flipped classroom, and our empirical, rather critical considerations can inform this line of research (see in particular [Isomöttönen and Tirronen 2013]).

2.2.5. Debate on MOOCs. Ferreira [2014] argues that it is important that classroom pedagogies are reviewed in reference to massive online open courses (MOOCs) and 
their likely popularity in the future. On the other hand, Petre and Shaw [2012] have presented their reservations about what kind of learning can result from distance learning if dialog fostering critical thinking is missing. They note that, with free online courses, investments in true personalization are not likely to occur, and that simply providing information online does not imply quality education. Martin [2012] again notes that components such as auto-graders in online environments will not replace individual mentoring of learners, and that individual differences are difficult to address with MOOCs, since some learners are still learning to learn, whereas advanced learners become bored. Our present action research project highlighted this challenge of differences in pace of learning in an environment where students were required to undertake independent study and complete a lot of challenging practical coursework [Isomöttönen and Tirronen 2013].

The pedagogic principles of MOOCs have been reviewed by Glance, Forsey, and Riley [2013]: Flexibility is the main argument for online learning. Short videos are intended to increase focus and attention. Quizzes and assessment components are linked with retrieval and mastery learning in terms of formative assessment. Self- and peer evaluation are intended to enhance assessment, while online presence is expected to increase peer assistance. As regards mastery learning, early definitions by Bloom [1968] signify instruction that matches with the individual's characteristics such as aptitude, perseverance, and time needed for mastering particular contents under study. As explained by Bloom, this approach implies the need to identify the progress of learners and use of the wide range of instructional methods. The Bloom's definitions thus oppose "same for all" instruction in classrooms and underpin well the present study on a flexible learning condition. We will nevertheless use the term in a formative sense, in connection to learning environment elements, which enable the learner to recognize his or her own stage in learning: quizzes and automatic assessment tools with automated feedback are currently found in our target course environment. It should be noted that we have complemented such components with teacher comments on student exercises on an individual or group basis. The number of students on the course has been small enough to enable individual comments on the programming exercises, although we acknowledge the high workload this entails.

Our research stance is neither to verify distance learning nor to cling to the traditional lecture format. In our view, when distance learning is criticized, we should not forget to critically review massed lecture rooms filled with passive students-how much dialog takes place and how many teaching resources are devoted to personalization on freshman courses with large numbers of students, for instance? As reviewed by Glance et al. [2013], a body of literature suggests that academic achievement on online courses compares with or even surpasses achievement on traditional courses.

\section{ACTION RESEARCH IN BRIEF}

Action research, originally outlined by Lewin [1946], is a form of inquiry in which research aims for social change by improving social practice and understandings of that practice. Action research proceeds in cycles consisting of planning, action taking, and observation and reflection.

Minimum requirements for a study to be contextualized within action research methodology include a focus on social practice, the insider role of the researchers, and the goal to involve those whom the research concerns [Carr and Kemmis 1986, pp. 165-166]. Education is a known field of social practice suitable for action research; Many scholars have accordingly adopted the term 'educational action research.' The insider role means that research is carried out by or with insiders, rather than on them [Herr and Anderson 2005], implying that teachers as researchers or interested teachers working in close relationship with researchers should fall within this definition. In 
the higher education context, student populations change from one course or time to another; in our view, this draws attention to the task of conceptualization during the reflection elements of the research project, so as to increase the transferability of the research to other groups, times, or situations.

The literature differentiates between practical, critical, and technical action research, reflecting Habermas' knowledge-constitutive interests [Carr and Kemmis 1986, pp. 202-205]; see also [Clear 2004; Grundy 1990]. "Practical" refers to research addressing emergent practical concerns and improving understandings of those concerns through action. "Critical" refers to the emancipatory character of action research, while "technical" refers to the testing of scientific hypotheses. This differentiation can be understood through the role of researchers. In technical action research, external facilitators are in a dominant role, and the study principally tests external hypotheses. While research of this kind potentially leads to improved practice, the results may principally contribute to theoretical knowledge of a particular research field. In practical action research, the role of authentic participants in the research context is more substantive. However, it is critical action research that is the most illustrative case of authentic participants aiming to improve their practice and the situations where the practice is enacted. Educational action research is usually practical and critical, with teachers as researchers addressing local problems. With respect to the epistemological stance of action research, Carr and Kemmis [1986, p. 215] point out the difficulty with both technical means-ends studies (positivism) and intepretivist studies (relativism) as means of change. As we would phrase this shortly, positivism drawing on external theory tends to ignore local theorizations emerging from an action research project, while relativism by definition implies the difficulty of which perspective to follow in action taking if you can "go with any". On this ground, Carr and Kemmis refer to the "activist" nature of educational action research.

Action research addressing local problems from an activist stance thus implies a departure from positivist epistemology and the related "grand" and "fixed" generalizations. There are, however, definitions that allow an action researcher to consider generalizability from a local base. Classic grounded theory speaks of substantive grounded theories, which are conceptualizations emerging from and then operating within a particular empirical area [Glaser and Strauss 1967, pp. 32-33]. Accordingly, several scholars have turned their attention to theorizing within action research methodology, by reference to grounded theory [Poonamallee 2009] and "local theory" [Genat 2009], or by identifying with thinking on the critical realist project [Friedman and Rogers 2009]. Friedman and Rogers [2009] note that an action researcher might reject the possibility of incorporating theorization owing to a facile association with positivism. Reliance on middle-range grounded conceptualizations, which are open to modification, do not necessitate positivist epistemology; see, e.g., Maton and Moore [2010].

The historical and social dimensions of action research must be also mentioned [Carr and Kemmis 1986, p. 182]. Thus, an action researcher confronts a need to consider his or her practices in the institutional context, from historic and social perspectives. Action research itself is a social process framed by the need to dialectically contrast between micro and macro levels. Subjective experiences and observations need to be understood in reference to possible constraining factors locally and in the wider domain of the action. We connect the present research with a wider historical and social setting (the previous contextualization section).

\section{ACTION RESEARCH IN THE PRESENT STUDY}

Figure 2 summarizes the present action research project. The research began from practical concerns related to 'wastage' experienced in teaching the topic of functional programming through traditional lecturing: basic syntactic issues could have been 


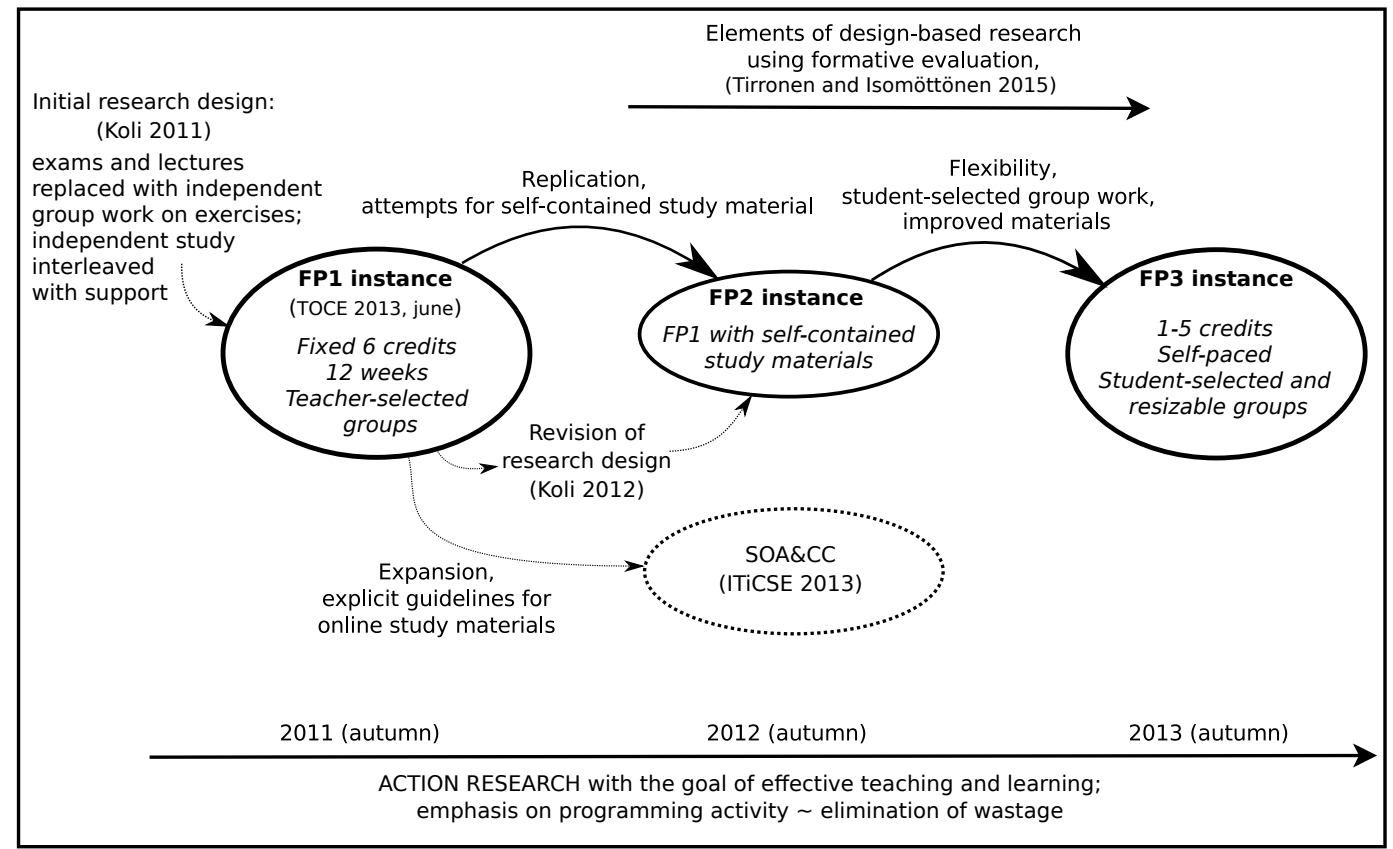

Fig. 2. Action research project illustrated. The project started from making a lectured course heavily practice-oriented (FP1). Later on, the course materials were redesigned (FP2) and the course was made flexible to study (FP3). During FP1, the exercise-driven course was implemented in a 12-week period and using a fixed course size, while FP3 made the course truly adjustable for the student. The abbreviation SOA\&CC stands for the course name Software Oriented Architectures and Cloud Computing.

studied independently, while more practical programming would have been needed to improve communicating the abstract concepts of functional programming to the students. This identification of a local concern caused us to refer to and follow action research methodology. The research question became: How can we harness student and teacher resources toward learning and teaching this difficult topic? We began with a course model different than a traditional lectured computing course, which we deemed to be a constraint with such a difficult course topic. We were interested in students' reaction to and acceptance of a revised course and the potential obstacles that we would face, which would then require further actions.

The first iteration (see Figure 1 and FP1 in Figure 2) already revealed that students preferred the new course model (learning by doing) to a traditionally lectured course, although several issues that constrained student learning were observed [Isomöttönen and Tirronen 2013]. Group work, which we included in order to foster peer support, posed a number of problems, such as different skill levels and scheduling issues. Programming being the fundamental skill for computing students, the way in which we provided peer support for students seemed to require further action. We also noticed that running the course in weekly cycles revealed that not all students were able to keep to the expected schedule, leading to problems with learner roles in groups and personal frustration. A major challenge was also how students could make a synthesis of the learning topics under the conditions of independent study. The research observations from FP1 were confirmed, and more detailed observations about the challenges regarding students' adoption of a self-directed learning mode were made in a study that applied the course model to another course [Isomöttönen et al. 2013]. 


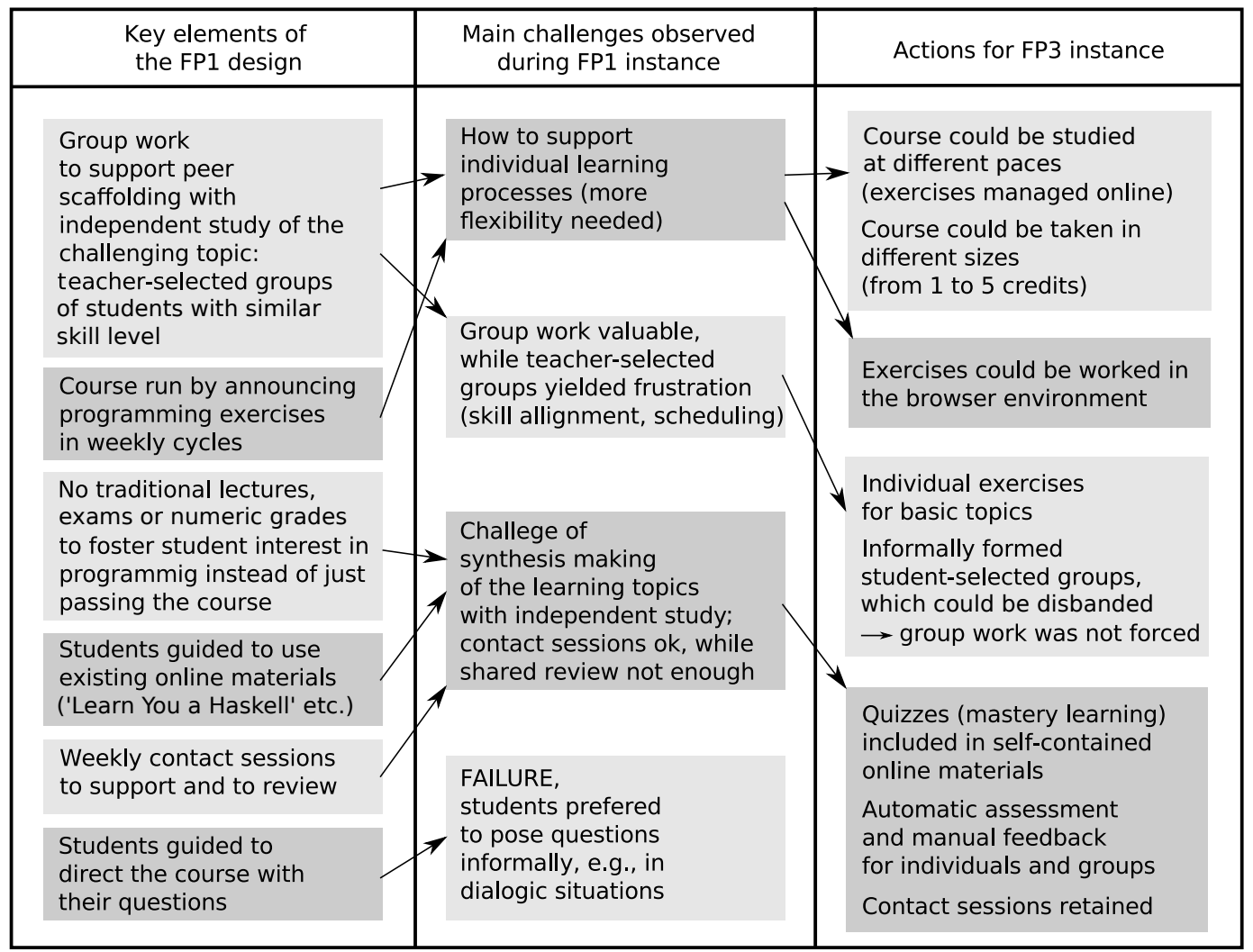

Fig. 3. Action research process underpinning the present study

With the second action research iteration (FP2), we focused on developing theoryinformed, self-contained learning materials so as to support students' independent study based on the observed challenge of synthesis-making [Tirronen and Isomöttönen 2012]. Given an unexpectedly high workload arising from the difficulty in creating theory-informed materials, the course was run with materials that were still undergoing development and refinement. From this we learned that having self-contained materials online does not automatically secure success, but that the materials need to be explicit and capable of explaining the content efficiently (see [Petre and Shaw 2012; Martin 2012]). We observed, however, that, using the online materials that we had identified as having the attributes of explicitness and explanation, the students completed the exercises with less difficulty. We therefore continued with theory-informed material design, which added an element of design-based research with formative evaluation to our action research project [Tirronen and Isomöttönen 2015].

The research focus in the present article is the third action research iteration (FP3), which attempted to overcome the difficulties of the first action research iteration, as described in the next section.

\subsection{The study of FP3}

Figure 3 describes the background and action taking for the FP3 course. Changes were made to the role of group work, learning materials, and the ways in which the course could be studied with regard to pace and size. The basic course design was still in 


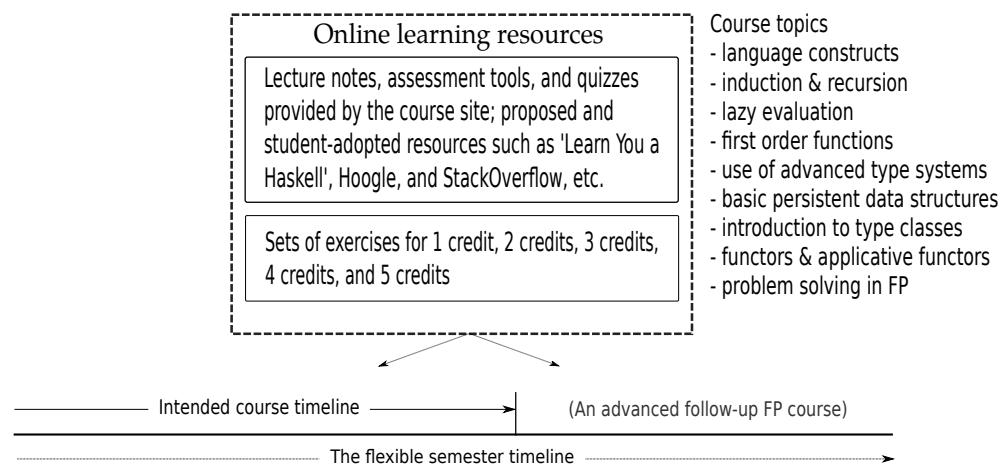

Fig. 4. The flexible setting devised for the FP3 course. Students knew the intended course timeline, and they were informed that they could complete the exercises flexibly during the semester. It must also be noted that another, advanced, functional programming course started in the latter period of the semester.

place with pass/fail grading, with no traditional lectures nor exams, and with weekly voluntary contact sessions (see Section 2.1 ), while students could now study the course much more flexibly. They were informed of the intended course timescale (two months) but also about the possibility of doing the exercises throughout the semester (a little less than four months) according to their personal progress and schedule. Excluding individually returned, automatically assessed exercises for basic topics at the beginning of the course, group work was encouraged but not forced. Groups were informally formed and students selected and could even be disbanded during the course. All exercises were made available at the beginning of the course to support individual study at different paces and we had intensively developed our own self-contained learning materials. The course site now included lecture notes on the course topics, enabled programming in the browser environment, and provided quizzes and automatic assessment tools. Figure 4 illustrates the flexible setting of the FP3 course.

For evaluation, we used a qualitative survey, study activity data, and a teacher narrative. The following survey questions explored the students' views of the FP3 course at the end of it:

- Q1: What has been the biggest help for you during the course (group, course site, exercises, supervisors, contact sessions, web, the textbook "Learn You a Haskell", something else)?

- Q2: Was there something missing? What could have further supported your learning?

- Q3: Did you have to search for materials outside the course website (web, e-books, StackOverflow, etc.)?

- Q4: Describe your group experience.

- Q5 (three-point Likert scale): Did you identify any of the following group patterns in your group work? (Patterns are based on the previous action research iterations.)

- Q6 Can you describe your role in some other way?

- Q7: Did the role you were given in your group enable you to learn well? What kinds of challenges did you encounter?

—Q8: Did your role change during the course? Did it affect your studying?

- Q9: The course was flexible in many ways (e.g., individually defined credits and pace of progress, possibility of distance learning). What do you think of that? Could you keep up with your schedule? Do you feel that the flexibility was an advantage or did it impede your work?

- Q10: Describe your motivation during the course. 
The questions were informed by the previous findings, reflecting the continuity of the action research: Q1-Q3 relate to the conditions of independent study and the related challenge of synthesis making, Q4-Q8 aim to foreground potential issues related to the learning possibilities of individuals in the group work context, while Q9 asks students to elaborate on the flexibility of the course. Q10, which was also included in the FP1 study, was a general question that potentially reveals the emerging aspects of the students' study processes. The main research instrument was the collection of qualitative data with open-ended questions. With regard to group work, we included a Likert scale question (Q5) based on our previous results. The survey questions were largely the same as or similar to those in our previous research iterations (see [Isomöttönen and Tirronen 2013]). In our minds, having similar kinds of survey questions added to the systematicity of the research process. Taking particular actions (see Figure 3), we study whether we see similar challenges to those we saw previously, or whether we see improvements or new challenges.

The orientation of the analysis is qualitative, with the analysis method resembling thematic coding [Attride-Stirling 2001] and pattern coding [Miles and Huberman 1984]. Further, our analyses and thought process were naturally and inevitably framed by the continuum of the action research process (Figure 3 ). In action research, we believe it is important to attempt to identify the main knowledge claims that can inform action. In this connection, we associate the action researcher's activist stance (see Section 3) with the possibility of middle-ground (cf. local) theory, which can be both drawn from and inform subsequent practice, and is reflected in the thinking of Glaser [1978] and more generally in the thinking of authors such as Moore [2000]. We think of generalizability in terms of the transferability of knowledge claims into similar educational situations and improvement efforts.

Theoretical hypotheses (main knowledge claims) may be identified with comparative thinking. As we identify noteworthy points and regularities in our data and observations, within a single course instance data and in the continuum of our action research project, we naturally compare between them such that we take into account the conditions where they emerge. This interpretation chimes with that of Lewin [1946]:

The research needed for social practice can best be characterized as research for social management or social engineering. It is a type of action-research, a comparative research on the conditions and effects of various forms of social action, and research leading to social action. (Emphasis ours.)

We began the analysis of the survey data by coding the prominent aspects through comparative thinking and using pen and printed data sheets. Then, the data was transferred into a spreadsheet, and the survey answers were systematically rereviewed. For questions addressing the conditions of independent study (Q1-Q3), we present a rough categorization with frequency information followed by a qualitatively oriented discussion on main patterns. For group work-related questions (Q4-Q8), we arranged our interpretation into a display that captures all the key aspects received from the open-ended group work questions. The students' comments on flexibility (Q9) were first divided according to their nature, and then the main themes within the resultant divisions were extracted. We clearly acknowledge the exploratory nature of the analyses, which is shown in the different kinds of presentations employed. A particular presentation was selected on the grounds that we considered it as enabling us communicate to the reader the noteworthy aspects and regularities that we, through iteration, saw in the data.

We also examined students' study activity data regarding the time slots and volumes of exercise submissions. These distributions were examined in light of the survey data and student success (dropouts vs passed). We were hence able to compare between ac- 
tual submission activity and what students reported from their experience (survey), and make comparisons within and between dropped and passed students. The value of the data of this kind, in understanding students' study processes, is acknowledged [Zimmerman 2008]. All numbers included are descriptive statistics fitting the qualitative and explorative orientation of the analyses.

As in our previous study [Isomöttönen and Tirronen 2013], we also collected a teacher narrative of the course. This enabled us to increase "evocativeness" and incorporate two kinds of value systems (students and teacher) when attempting to identify patterns (knowledge claims) that can inform subsequent research efforts. While the first author began the evaluation by reviewing the survey data, the second author first prepared a narrative summary from his teaching perspective. This narrative is available on the web ${ }^{2}$, naturally affecting our evaluation and conclusions. We only present particular extracts from it in this article to emphasize a teacher view when interpreting the other data.

\subsection{Roles and the nature of action research project}

Throughout the research project, the first author acted as a researcher, while the second was both a researcher and the teacher of the functional programming course studied. Both authors are teachers in the same department, and thus are thoroughly familiar with the environment- that is, we are both insiders. Throughout the project, we had intensive reflective discussions on the various observations about the course and the directions that we might take. We designed the data collection methods together and were able to make use of our two different positions in the data analysis. The first author's background is in teaching and studying project-based courses, specifically looking at group work issues, while the second author possesses expertise in functional programming languages. On the grounds of the definitions by Carr and Kemmis [1986] (see Section 3), our authentic roles indicate practical and even critical action research.

During the course instances, students have not acted as researchers but as regular course participants. In the present higher education context, a new course population enters the course each autumn semester, and in this regard the question of how to engage students with a multi-year course development process is not simple to answer. Involving them in planning and evaluation activities, while retaining a natural course setting for reasonable research, is a future research question for us. On the other hand, we have involved students who have completed the course in the closely related research, one student co-authoring a study with us [Tirronen et al. 2015] and other students undertaking master's thesis work. These collaborations have addressed specific challenges in learning functional programming and complement the present action research. Fitting the action research emphasis on participation, they increase engagement between students and us as teacher-as-researchers at the department.

The action research project has nevertheless been shown to course populations during the course instances, as we have collected research data and accordingly informed students of our ongoing research. During particular phases, we encouraged instant and continuous feedback. In particular, when we began to develop our own online materials, we included feedback forms allowing anonymous feedback in every section of the course site, noting students that any commentary is welcome as we are continuously developing the course site.

The present efforts on course didactics evidently indicate practical action research. It should be noted that these efforts do not associate with mere impulsive experimentation by teachers. The research project is anchored to the local worry of how to teach

\footnotetext{
${ }^{2} \mathrm{http}: / /$ functional-programming.it.jyu.fi/narratives/narrative.html
} 
a difficult topic. The literature indicates functional programming as a level-field for students, including the delivery through Haskell [Chakravarty and Keller 2004]. Our students also face a transition from imperative languages to a functional one, which is known to cause additional difficulties [Clack and Myers 1995]. The situation described makes louder the link with critical research in terms of empowering students through didactics that allow and encourage substantive effort with the course contents.

Taken together, we are of the opinion that we are exercising practical action research with some characteristics of critical research included. The research project can later more substantively exemplify emancipatory (critical) research. Through further research on the causes underlying student self-regulation difficulties reported in the present article, we anticipate to find detrimental cognitive strategies, which can inform action taking in a wider departmental context (see discussion in Section 6).

\subsection{Validity considerations}

The major test of rigor is that improvement occurs such that participants increase control over their situation. Action research scholars [Greenwood and Levin 1998; Melrose 2001; Heikkinen et al. 2007] speak of workability, meaning that generated hypotheses work in the specific context-that is, they are actionable. Workability closely relates to the empowerment of the participants. In our case, this links with our intention to harness teacher and learner resources genuinely for learning a difficult course topic. The present research improved our understandings of how to run the course in this regard.

Melrose [2001] believes it is important for an action researcher to repeat the research cycle in order to be able to react to emerging concerns; we agree and have acted accordingly. She also speaks about sub-projects that 'spin off the center' of the project; we applied our course model to another course (Software Oriented Architectures and Cloud Computing (SOA\&CC)) to further clarify, refine, and communicate outward the hypotheses that initially emerged. With regard to the credibility of the research group, Melrose advocates constancy, meaning that the group stays together for reasonable hypothesis-building. She further notes that the research group should preferably possess the necessary expertise. Our roles as described above match these requirements.

Data collection in our research project was rooted in continuous discussions. We deliberately collected both student views and teacher narratives such that the first author, being more fully in a researcher role, initially interpreted the student data, and then an authentic teacher narrative was contrasted with patterns emerging from the students through discussions. Adding the study activity data to the analysis further increased a triangulation effect. We were able to look at our interpretations from the qualitative survey data in light of the study process data and hence avoid rash conclusions. This way the analysis could also reach the whole course population and the phenomena therein. Shared data collection design and triangulation are rigor attributes suggested by Melrose. With the FP3 course, and also earlier, we anchored our analysis on (reviewed first) qualitative survey data, which we believe, with our relatively small number of students, increased "evocativeness," an aspect of validity discussed by Heikkinen, Huttunen, and Syrjälä [2007].

A potential concern in the FP3 study could be the survey respondents representing only the students who liked the course and managed it well. The survey was sent to all registered students. We found submissions from 92 different students in our submission system. A total of 34 students (37\%) responded to the survey. However, 43 out of the 92 students had only "peeked" at the course, demonstrating a low number of submissions, as is detailed in the results section. In this light, we deem the number of survey respondents to be tolerable and note that 8 of the 34 respondents were dropouts. In our thinking, many of our specific survey questions might have been difficult if not 
impossible to answer with little or hardly any participation. We also note that the results did not indicate that survey respondents were simply students who liked and managed well the flexibility of the FP3 course, for instance. The important reason for including both the survey data and the study activity data was to be able to counteract potentially biased or narrow interpretations, as discussed above.

In retrospect, we would be more careful in formulating group pattern assertions that were posed to students: some of the items in Table II consist of more than one claim and might have been difficult to answer. Related to these items, we also lack useful data on the amount of group work attended by individuals. However, we found the data from these assertions to be in line with other data on group work and important in making conclusions (cf. triangulation).

We found the design of the data collection to be, overall, a challenge. In particular, we have been afraid of reporting on too small, single studies. In this regard, we remind ourselves and wish to emphasize here that an action research project is a lengthy personal engagement, and needs to be understood as a continuum underpinned by intense previous thinking and informed action (see [Greenwood and Levin 1998, p. 122]). Accordingly, we have found it beneficial to explicitly frame the research thought process, as we do in Figure 3. In our experience, despite studying a fairly uncrowded master's level course, the qualitatively oriented explorative analysis is an onerous task as there is the requirement of actionable conclusions.

As this study reports on self-regulation difficulties under flexible learning condition, the impact on such difficulties of the target course being elective must be discussed. First, we note that the course has been elective throughout our action research project; our comparative thinking on the continuum of the project should be reasonable in this respect. Second, we have witnessed a high interest in the course topic among students and believe that students genuinely want to complement their programming skills by this course. Third, the other courses that students can take in place of functional programming are also challenging, although the present course with its exercise-driven form is known to be taxing among students. Fourth, study difficulties similar to those presented in this article have been reported by other scholars [Bell et al. 2001], which in our thinking increase the plausibility of our conclusions. Altogether, we speculate that electiveness boosted the effects we saw, i.e., the students' self-regulation difficulties under flexible condition. The course was recently made mandatory to students specializing in programming languages, providing a research opportunity for a natural experiment in the near future: we can observe how these students select to study in terms of a flexible credit scale and compared to those taking an elective course.

\section{RESULTS}

The sections below first summarize the student survey answered by 34 students. Thereafter, we will complement the analysis with the study activity data and a discussion on the pass rate.

\subsection{What were the conditions of independent study?}

5.1.1. Background. We previously found that under conditions of independent study, students encountered great difficulties in making a proper synthesis of the learning topics. On these grounds, we began to develop our own learning materials: the course website, which includes quizzes and coding boxes, as well automatic assessment tools. Attempts were made to have a self-contained site that could serve as the main learning resource. This section synthesizes students' answers to questions Q1-Q3, which investigated the conditions of independent study. 
5.1.2. Main observations. Students received help from multiple sources, meaning that there was a lot of variation in the data for Q1 and Q2. Table I summarizes students' answers to questions Q1-Q3.

All 34 survey respondents replied to Q1. Eight answers referred to the principal use of online materials. Of these, two answers enabled us to interpret that the student practiced distance learning due to scheduling issues, and two other answers showed that the student clearly preferred studying alone as a distance learner. Altogether, 15 other answers referred to help both from people (peers in the group and supervisors, i.e., the course teacher and TAs) and online materials, while of the remaining 12 answers, nine emphasized (some also mentioned the value of the e-learning tools) help received from people. Moreover, one respondent raised only the use of the compiler and one referred just to the exercises as the learning enabler. Overlapping with these categories, eight answers brought up exercises as the learning enabler. These observations suggest that this student cohort benefited from the course that allowed for both distance (online) learning and interaction through contact sessions and group work, and experienced the exercise-driven course as useful for learning.

A total of 30 students replied to Q2, of which nine answers included an explicit wording that the student did not need any additions to the course arrangements. In these answers, the students generally appreciated the course's exercise-driven nature and the course as-is. The other positive theme was the student requests for more online tools, which they had (across the survey data) experienced as useful. Then, there were scattered suggestions, such as including discussions on the similarities and differences between c family languages and Haskell functional language. One student comment called for more examples, while two others indicated a preference for theory being introduced before exercises. A few students commented on their difficulties with allocating time to study the topic. Criticism is also fairly scattered and mostly concerned the parts of the material that were experienced to be unclear, suggesting that we need to continue structuring our course site.

All 34 students replied to Q3. Nearly all students $(32,94 \%)$ had used materials other than those provided by the course site-Google, StackOverflow, Learn You a Haskell, Hackage, Haskell.org, Zvon.org, and Hoogle. Students regarded search engines as a straightforward way to seek for help and used multiple resources for finding alternative explanations when a particular resource turned out to be inadequate.

With our open-ended questions, the main interest was interpreting the answers with qualitative orientation through comparative thinking. The resultant patterns are reviewed below.

Feedback enabling mastery learning. The students appreciated the coding boxes embedded in the materials, as this allowed them to test their code immediately. Similarly, they praised the quizzes and automatic assessment tools for their immediate feedback and confirmation.

\section{Student answer to Q1: “Check your understanding” sections of the material were excellent. \\ Student answer to Q2: If only all the exercises had that nice automatic check. You immediately know whether you succeeded, as you are provided with feed- back.}

The tools added to the course site seemed to beneficially enable formative evaluation. Let us recall that we use the term mastery learning the same the MOOC pedagogy does. We emphasize the formative characteristics of a learning process enabled by feedback (see Section 2.2.5). 
Table I. Summary of answers to Q1-Q3

\begin{tabular}{|c|c|}
\hline $\begin{array}{l}\text { Summary of Q1 - answered by } 34 \text { students } \\
\text { "What has been the biggest help for you during the course?" }\end{array}$ & $\mathrm{n}$ \\
\hline $\begin{array}{c}\text { Emphasis on people: } \\
\text { supervisors, group }\end{array}$ & 9 \\
\hline $\begin{array}{l}\text { Emphasis on e-resources: course site, particularly quizzes, AA-tools, } \\
\text { and browser coding boxes; various web materials }\end{array}$ & 8 \\
\hline Emphasis on both people and e-resources (cf. blended learning) & 15 \\
\hline Exercises alone (without any of the above mentioned) & 1 \\
\hline Use of the compiler & 1 \\
\hline Appreciation of exercises (overlapping with the first four categories above) & 8 \\
\hline $\begin{array}{l}\text { Summary of Q } 2 \text { - answered by } 30 \text { students } \\
\text { "Was there something missing? What could have further supported your learning?" }\end{array}$ & $\overline{\mathrm{n}}$ \\
\hline $\begin{array}{l}\text { No critique, satisfaction } \\
\text {-liked the exercise-driven nature, liked course liked as-is }\end{array}$ & 8 \\
\hline $\begin{array}{l}\text { Increase useful arrangements } \\
\text {-learning tools: coding boxes \& AA tools (note: quizzes were highlighted in Q1 answers) } \\
\text {-exercises explaining the approach to be used }\end{array}$ & $\begin{array}{l}2 \\
1\end{array}$ \\
\hline $\begin{array}{l}\text { Personal and group challenges } \\
\text {-lack of time, longer course } \\
\text {-lack of motivation } \\
\text {-more time with group needed } \\
\text {-less group work to avoid delays }\end{array}$ & $\begin{array}{l}2 \\
1 \\
1 \\
1\end{array}$ \\
\hline $\begin{array}{l}\text { Cognitive challenge } \\
\text {-provide theory first } \\
\text {-more examples } \\
\text {-connectedness between exercises and web materials }\end{array}$ & $\begin{array}{l}2 \\
1 \\
1\end{array}$ \\
\hline Characterize the difficulty of exercises & 1 \\
\hline Provide guidelines for time management & 1 \\
\hline Increase support for project-like exercises & 1 \\
\hline $\begin{array}{l}\text { Criticism on running the course } \\
\text {-lack of clarity in materials } \\
\text {-videos provided late }\end{array}$ & $\begin{array}{l}3 \\
1\end{array}$ \\
\hline $\begin{array}{l}\text { Illustrate the transition from imperative to functional } \\
\text {-comparison between c family languages and FP/Haskell }\end{array}$ & 1 \\
\hline Non-informative (few exercises completed, difficult to comment on) & 1 \\
\hline $\begin{array}{l}\text { Summary of Q3 - answered by } 34 \text { students } \\
\text { "Did you have to search for materials outside the course website?" }\end{array}$ & $\mathrm{n}$ \\
\hline Yes (Google, StackOverflow, LYAH, Hackage, Haskell.org, Zvon.org, and Hoogle) & 32 \\
\hline $\begin{array}{l}\text { No ("At least not yet", } \\
\text { "Reviewing the libraries perhaps not counted as external material") }\end{array}$ & 2 \\
\hline
\end{tabular}

Provision for explanation. When the above preference for mastery learning (tools) was compared to other student preferences, we found a trend that students were rating as positive those aspects that had provided them with an explanation. For instance, the students who referred to the help received from supervisors also emphasized the value of explanation.

Student answer to Q1: Supervisors. You can learn a lot from documentation and books, but certain things you learn better when they are explained by someone who masters them. 
The appreciation of explanation was also observable in other details of the students' comments. For instance, one student referred to larger project-like exercises in a sense that the student would have preferred a discussional shared review (cf. receiving explanation) on these kinds of exercises. The student comment below in turn calls for more exercises that explain how a particular task should be approached, which enables the learner to connect the programming concept under study to particular problem contexts.

Student answer to Q2: ...In some exercises the mentioning of the technique ("implement using list comprehension", "implement using recursion”) helped.

In sum, we derived a kind of a "call for explanation" guideline from the survey data, which can be materialized by increasing quizzes that explain to the students the correctness and wrongness of their answers, as well as AA tools that provide feedback. We should also improve parts of the materials, including exercises, by explaining abstract concepts through in-use examples and by clarifying the contexts where particular techniques apply.

Counteracting the cognitive load challenge. Looking at the answers to Q2, students expressed concerns about the inadequate relatedness of exercises and web materials, and more examples were also requested. Moreover, there were comments suggesting that theory should be provided first, i.e., some introduction to the current topic is needed before the students embark on related exercises. In our interpretation, students were drawing attention to the cognitive load caused by the experience of scattered learning resources or too much unguided learning, suggesting that there remained room for improvement of the course materials to make them both more integrated and richer in explanation. Relatedly, one student suggested a difficulty rating of the exercises to increase the awareness of the exercises, and some comments referred to immature parts of the materials, mentioning consistency and small issues such as typographic errors.

Student criticisms were not strong in nature (26\% of Q2 answers expressed no critique but rather satisfaction, and the course site was highlighted among the important e-learning resources in answers to Q1). We include one example of a student appreciating improvements to the course site, one that advocates for the integration of learning tools and materials, and hence points to the resultant fluency from the learner's point of view.

Student answer to Q2: I longed for that separate code editor, into which you could have directly typed programs within the browser. Very often I opened particular exercises, which had the editor, such that I could test my code immediately. Ghci was handy, but I preferred the editor found in particular exercises.

Finally, to understand whether we had improved as for the cognitive challenge, which we saw as the outcome of the FP1 instance, we quote the teacher, who in his narrative, stated that through significant revision of materials,

the course seems much more palatable for the students than before and we receive very little criticism.

Further, in the teacher's experience, the increased possibilities for students to interact with the learning environment was now hampered by problems emerging from the flexible pacing of the course (as we will report later): 
Teacher: As for the present study, it seems that the positive changes, such as the increased interactivity, have been overshadowed by less successful experiments, such as the flexible pacing we introduced into the course.

We conclude that the added tools in the course site improved the conditions of independent study, and that the materials used in general did not considerably complicate students' study processes, although actions still have to be taken to fine-tune our own materials.

Variations in receiving help; provision for scaffolding. The students seemed to be in different stages of self-direction, which is suggested by the variations in the data. There were students who considered self-help to be a natural part of the work of a programmer, and who did not mention difficulties with learning from various materials.

Student answer to Q3: To some extent, but that's the point when you're programming.

Another student states: In abundance, while this same phenomenon applies to all courses, in particular programming related ones.

However, there were other students who seemed to be more dependent on help from people, as illustrated by their answers to the question about the biggest help they received during the course.

Student: Group, supervisors, and my own repeated work on the topic. Unfortunately, the literature on the topic would require more time to familiarize myself with.

Student: First, the group has been a big help, as every member thinks differently and someone in the group will grasp particular topics better than others. Second, the supervisors, without whom we would have not reached the stage where we are.

These variations speak for blended learning, where contact sessions allow for scaffolding for those who experience too big a challenge with independent studying using online resources. Similarly, aligned with blended learning, we interpreted differences in the extent to which the students preferred a social learning process.

Answer to Q1 from a student who earned 5 credits: LYaHfGG, Hackage, and Hoogle have been the most useful tools. Besides the course teacher, I have not discussed with anyone during the course, or attended any course session after the starting session, because I learn better alone.

Easy access vs. scaffolding. In answers to Q3, we found that the key reason for using various online materials is the easy access through a search engine. Students did not criticize the course materials, but they pointed out that for specific questions it is (understandably) easier to seek solutions by searching on the web. We could improve the self-contained nature of our course materials by adding a search functionality. Finding a particular topic effortlessly from the course site is likely to introduce a useful link between the exercises and lecture notes on the course site.

Students seemed to be aware of and use the procedure for searching for help from services such as StackOverflow (94\% had searched information on the web), while, as discussed above, they also demonstrated a need or a preference for explanation from people. Thus, familiarity with self-help (e.g., Google, StackOverflow) does not just translate into successful scaffolding. We again conclude the usefulness of contact sessions instead of, for instance, devising a fully online course, with all the students educated about self-help routines. 
Practice as the key enabler. Yet another aspect in the data that generally justifies our action research project was the appreciation of the practice-based course format. The need for practice was due to the difficult nature of the course topic.

Student answer to Q1: ...The exercises naturally provided enormous help; functional programming is clearly more difficult to learn only "in theory" as compared to object-oriented programming.

Student answer to Q2: Not really. I personally learn best by doing exercises, which were in abundance in this course. Doing the exercises was also supported very well.

Students' comments relevant to Q9 also emerged in the answers to Q1-Q3, as indicated by the patterns below.

Awareness of time management. The course structure was presented to students as a network consisting of learning topics and their connections, permitting flexibility and variability of pace. However, one student commented that a structure with clear modules and connections to time (schedule) would have been needed in order to improve his or her personal management of the coursework.

Student: Even though the course was flexible regarding credits, it would have been good to have some kind of "invisible" structure for maximum credit. Thus, some kind of dates clarifying the deadlines for particular exercises, helping to keep up with the "schedule."

Timing of help under the flexible condition. Another challenge related to flexibility was that, in contact sessions, students were at different stages with respect to course topics, which meant that it was sometimes difficult to receive help from supervisors.

Student answer to Q1: The group and the supervisors. I have had time only to be present during a few review sessions; they have been OK, but the only problem in them is that everyone is at a different stage with the exercises.

5.1.3. Summary. We conclude that independent study can be and was facilitated by adding quizzes, AA tools, and embedded coding boxes in the materials, and by improving learning materials overall. We also conclude that in order to enable explanations for a wide range of students, we should retain both contact sessions and online learning opportunities. Factors such as disconnectedness between exercises and other materials and flexible learning pace resulting in scattered needs in contact sessions hampered the effective learning support of individual students-in a sense, how students could receive explanation. Students agreeing that a practice-based course facilitates the learning of the difficult topic, together with their requests for more the useful tools on the materials and their criticism, encourages us to continue developing the materials. With this agenda, our previous concern, "the challenge of synthesis making" in the presence of independent study, is transformed into the guideline of "call for explanation."

\subsection{How to benefit from group work?}

5.2.1. Background. During the FP1 instance and SOA\&CC course, the same group patterns emerged from the perspective of student learning. While some of the groups established sufficiently democratic learning environments, some students explicitly expressed their frustration with group work. For FP3, we let students informally form groups if they wanted to do so. We also had a set of individual exercises at the beginning of the course to prompt all the students to go through the basics. In the following, 


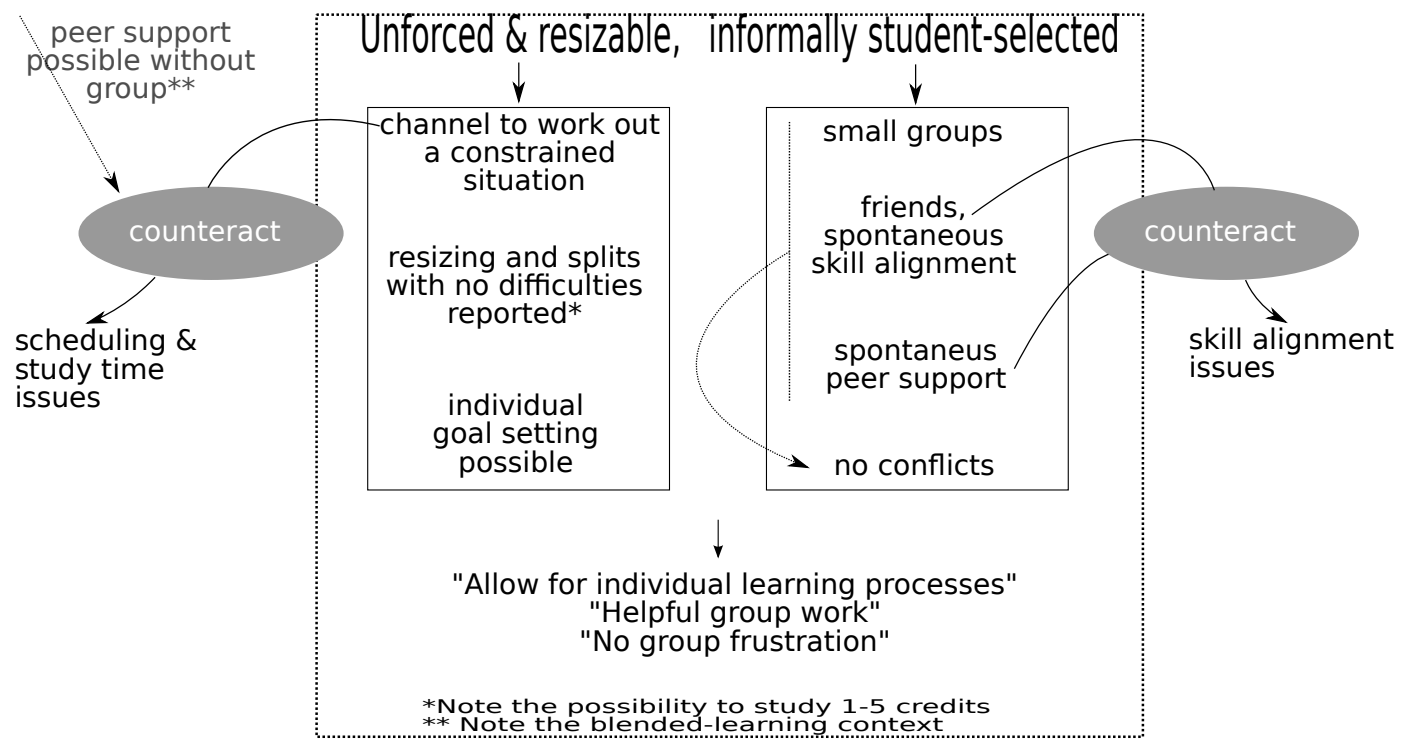

Fig. 5. Analysis of group work

we synthesize the students' answers to survey questions Q4-Q8. All 34 students commented on Q4, while for some students practicing distance learning, and perhaps because too many group questions were introduced, there were overlapping and empty responses among Q5-Q8 answers. We extracted the informative aspects across the group questions data and arranged these into a display, which is encouraged in qualitative data analysis [Miles and Huberman 1984; Attride-Stirling 2001].

5.2.2. Main observations. The analysis is illustrated in Figure 5. We first observe that informal selection by the students themselves yielded small groups, mostly of three students (44\% of the group submissions) or pairs (55\% of the group submissions).

Let us first look at the left-hand side of Figure 5. Unforced and modifiable groups resulted in the possibility of working out a constrained group situation. A student might leave the group and continue individually. For instance, a student with more study time available could abandon pair work and continue alone:

Student: I planned to take the course together with my work mate, but, as he could not really attend, I decided to work mostly alone.

Scheduling problems were also handled by disbanding the group, such that individuals continued the course alone.

Student: I tried to first work in a pair, but as we made progress at different paces because of scheduling problems, we decided to go solo.

In this connection, we note that peer support was possible without working in a group, which we consider to be attributable to the blended learning context.

Student answer to Q4: I did not work in a group. I did ask help from other course students, which was very useful.

We did not observe any clear frustrations in the data as to group modifications; the student comments explicitly stated that if a student left a group this did not harm the group: 
Student answer to Q8: The third member of our group had to leave the course for [his or her] other duties. This did not affect my own studying, and the group work went well in the remaining two-person group.

Relatedly, the following student quote illustrates a low threshold for honesty:

Student answer to Q4: Other members of my group hurried with the exercises, and at times I could not attend with them. At the 3-credit milestone they had done a major part of the exercises outside supervision sessions, and I myself could not thoroughly participate in this. Principally for reasons of conscience, I decided not to continue for 5 credits.

The student quote here refers to the possibility of completing the course with a variable amount of credits, which was likely to contribute to leaving the group with an emerging free rider role.

Furthermore, the resizable group work enabled students to put more effort into personally interesting exercises, enabling individual goal setting. That is, students could work mainly as pairs, but when the other student put a considerable effort into a particular interesting exercise, the exercises were returned individually.

The right-hand side of Figure 5 is reviewed as follows. The survey data suggests that students who grouped together tended to know each other (friend groups). Student comments reveal that such informal study groups, especially working as pair programmers to complete the exercises, were found to be highly useful and demonstrated spontaneous skill alignment.

Student: I have drawn a lot from group exercises. My friend and I are pretty much at the same level, even though the friend has made more progress with the exercises. Two heads think better than one.

We also conclude from the data that student-selected groups doing the coursework led to spontaneous peer support.

Student: At the moment my level does not quite match with the other two in my group, but my group members have persistently tried to keep me up with their level.

These raised aspects, the spontaneous skill alignment and spontaneous peer support in student-selected (friends) groups, thus seemed to counteract skill alignment issues. We observed indications of shared work rather than simply splitting up the weekly exercises between group members. The resultant positive tone (no conflicts) in the students' group work comments is in line with the observations that emergent challenges were naturally settled with unforced and resizable groups.

Two viewpoints in the data not captured by Figure 5 must be mentioned. In our report on the SOA\&CC course [Isomöttönen et al. 2013], we noted that distance learners reported difficulties with participating in group work, whereas with the present approach, such students could attend individually throughout the course. Several students also noted in the group work questions that they tended (or preferred) to work at home as distance learners, which the present approach made possible. The other viewpoint is the laziness indicated by or admitted in student comments to Q7.

Student: I am a very lazy person, so I did not do the work outside the contact sessions as much as I should have done in order to keep up with the schedule.

Student responses to Likert-scale question Q5 in Table II accord with our observations and the interpretation of the qualitative data, i.e., that group work was useful 
Table II. Students' responses to group patterns

\begin{tabular}{|l|l|l|l|}
\hline $\begin{array}{l}\text { Q5: Did you identify any of the } \\
\text { following group patterns...? }\end{array}$ & $\begin{array}{l}\text { I did not observe } \\
\text { this }\end{array}$ & $\begin{array}{l}\text { I observed this to } \\
\text { some degree }\end{array}$ & $\begin{array}{l}\text { This describes my } \\
\text { role well }\end{array}$ \\
\hline $\begin{array}{l}\text { ITEM 1: You worked indepen- } \\
\text { dently, while the group pro- } \\
\text { vided a support safety net }\end{array}$ & 13 & 16 & 0 \\
\hline $\begin{array}{l}\text { ITEM 2: You took care of your } \\
\text { own learning, and both learned } \\
\text { from and taught others }\end{array}$ & 6 & 11 & 12 \\
\hline $\begin{array}{l}\text { ITEM 3: You took a team } \\
\text { leader role and managed prac- } \\
\text { tical things such as submis- } \\
\text { sions and distribution of work }\end{array}$ & 21 & 6 & 2 \\
\hline $\begin{array}{l}\text { ITEM 4: Your hardly partici- } \\
\text { pated, and took advantage of } \\
\text { peers' answers }\end{array}$ & 24 & 5 & 0 \\
\hline $\begin{array}{l}\text { ITEM 5: You tried, but found } \\
\text { it persistently difficult and you } \\
\text { felt that you could not follow }\end{array}$ & 20 & 8 & 1 \\
\hline $\begin{array}{l}\text { ITEM 6: You tried (perhaps un- } \\
\text { consciously) to hurry on to par- } \\
\text { ticular exercises, so that you } \\
\text { could do the ones you preferred } \\
\text { before the others in the group } \\
\text { got to them }\end{array}$ & 25 & 3 & 1 \\
\hline $\begin{array}{l}\text { ITEM 7: Because of your previ- } \\
\text { ous knowledge, you received a } \\
\text { dominant role in the group }\end{array}$ & 28 & 0 & \\
\hline
\end{tabular}

and that there were hardly any frustrations-we acknowledge that the table numbers are only suggestive, as the survey respondents included distance learners and groups were resizable. We compared the ratings with the qualitative comments. As for ITEM 7, for instance, we noticed that the one selection of "dominant role" came from a student who did and preferred individual work. The selections hence fully indicate that there were no dominant roles based on previous experience, which supports the interpretation of spontaneous skill alignment. As for ITEM 6, the same individual worker had stated that he rushed for particular exercises. Of the three mid-scale selections, one relates to the self-experience of being an "overeager", and the other two do not indicate a negative overtaking of the work. Looking at ITEM 4, which potentially indicates free riding, we noticed that of the five mid-scale answers, two belonged to distance learners, one to a student leaving the group with less credits than others (quoted above), one to a student whose group had found it difficult to share work for particular exercises, and one to a high-achieving student likely commenting about how work was shared with particular exercises.

We can enrich the previously found patterns in Table II by noting that in the emergent balanced groups, leadership naturally varied with the daily mood of team members. Another group role-related detail was student appreciation of gaining first-hand experience instead of having a mere spectator role.

Finally, with this survey data, we were left with the question of how "accidental" the group splits and useful peer learning and support really were, and thus how attributable these aspects were to course conditions. Here, we note the different tone in student data as compared to our FP1 instance. The previous group frustrations are illustrated and commented on below: 
Student of FP1 course: Differences in skill are remarkable among the inexperienced students also.

$\Rightarrow$ Present reflection: Grouping based on teacher-selection with an attempt to group students with similar skill levels does not promote skill alignment sufficiently.

Student of FP1 course: Although the experience of group work is valuable, the workload is here too arbitrarily divided.

$\Rightarrow$ Present reflection: Teacher-selected group work led groups to persist regardless of the difficulties. The FP1 course started by forming the groups during a teacher-driven session, and students were never told that they could not leave the group. This omission and the teacher-driven aspect seemed to lead to problematic group situations that were "waiting for intervention."

Further, we refer to the teacher impression of abated free riding over the course instances. In his narrative, the teacher clarifies that

...I am drawn to conjecture that the very good passing rate of FP2 had more to do with the less able students free riding through the course on the backs of their more dedicated fellows rather than my efforts of improving the course... [The grouping procedure of FP2 was similar to that in FP1.]

...I also suspect that the possibility to honorably drop out with one or two credits [FP3 is being referred to] might have helped to reduce the number of free riders... []

With respect to the last quote above, our data from the FP1 course indicated students experiencing anxiety when being in a free rider role. A future study should investigate dropping out across several cultures to understand if the feature reported here is specific to a culture or country.

5.2.3. Summary reflection. The present evaluation of the group work reflects the observation that student-selected teams tend to naturally comprise students with similar skill levels and lead to fewer conflicts than in teacher-selected teams [Oakley et al. 2007]. In our data, the students reported working with peers at quite similar levels to themselves and with similar goals, generally without experiencing any frustrations. As discussed by Oakley et al [2007]., some studies suggest that teacher-selected teams lead to better learning experiences, while our action research project signifies that useful peer support emerges spontaneously from student-selected teams. One known challenge of student-selected teams, which tend to consist of friends, is a difficulty in addressing conflicts [Hagan et al. 1999]. The present approach-particularly allowing students to flexibly rely on either individual or group work-has likely counteracted this issue.

We have now used several strategies and consider that in our specific contextprogramming, specifically the difficult topic of functional programming-informally decided, resizable, student-selected groups are a better approach in terms of spontaneous peer support and fewer conflicts and frustrations. It must be clearly emphasized that we are looking for a solution from an action research perspective, rather than generally claiming that one grouping approach is superior to another. The present project called for a solution that makes peer support possible without student frustration, which might constrain learning and demand that teachers spend a great deal of time on conflict resolution.

Fincher et al. [2001] address group formation by conceptualizing the pros and cons of many alternatives: In line with the discussion above, they report that teacher selection, for instance based on "dis-affinity", introduces the challenge of starting with new 
people but also learning possibilities arising from such a condition. Benefits of student selection include that such groups, typically based on existing relationships, contribute to early progress. On the other hand, student selection is noted to preclude students from breaking out of learned habits. As an aside, when we previously used teacher selection, we tried allocation by self-evaluated skill (an option discussed by Fincher et al.). However, homogeneous groups did not emerge in the degree hoped, which might be due to the difficulty of making self-evaluations comparable and the fact that students were facing a transition from imperative languages to a functional one. Altogether, we identify with pros-and-cons thinking in which the context or the planned function of group work plays an important when deciding on this course attribute. The conceptualizations by Fincher et al. concern group projects and hence naturally omit aspects such as "resizability". This observation simply emphasizes the importance of context: our course with its primary focus on the core skill of (functional) programming was easily tailored to allow resizable groups.

\subsection{What did flexibility entail?}

5.3.1. Background. Flexibility here means that the course could be taken in different sizes (from one to five credits) and studied at different paces. This flexibility was introduced to take into account individual learning processes arising from different skill levels and practical scheduling issues.

5.3.2. Main observations. A total of 33 students answered Q9. Excluding one answer that was a remark on the exercises, unrelated to the attribute of flexibility, the answers $(n=32)$ are divided into three main categories by their nature: contradiction, positive, and negative.

A prominent feature of the data was the contradiction that students appreciated the flexibility of the course while at the same time, they had considerable difficulties in working under such conditions.

Student: Flexibility itself is a really good thing, while for me the lack of deadlines led to exercises remaining unfinished...

Interestingly, nearly half the answers $(15,47 \%)$ were of this kind, indicating that the students felt good about flexibility but could not exert control over their coursework without an external pull. Students reported the temptation to downgrade their learning goals, resulting in low performance in terms of unfinished exercises. Given the flexibility of this course, students also commented that they began to pay more attention to the obligatory (non-flexible) courses being studied during the term (see the third quote below).

The answers that expressed greater appreciation for the flexibility $(10,31 \%)$, along with the positive fragments of the above-mentioned contradictory answers, reflect students' opinion that flexibility is well suited to elective courses, which they attended principally for the sake of learning. Clearly, students seemed to enjoy the feeling of learning orientation that emerged from the flexible conditions.

Student: The flexibility worked damn well in this kind of elective course... because learning is the only motive for being in the course, it is reasonable not to have any strict schedule... More of these, please.

Some students noted that course flexibility allowed them to schedule their courses better during the term or made distance learning possible; for some, the flexibility was the reason they were able to attend the course in the first place. The students also appreciated the fact that they could be rewarded for their work at their individual level of goal setting. 
Student: ...I thus liked the flexibility and in particular the aspect that one was allowed to regulate the workload. If one would encounter really difficult topics in the course, such that one could not grasp at all, the course completion would not hang in the air, but a few credits could be achieved.

An interesting positive aspect is that regardless of the above-mentioned contradiction, students seemed to connect the flexibility of the course (and their good feelings about it) with motivation.

Student: In my view, flexibility was advantageous in a course of this kind, and I noticed that I concentrated more on other courses. The number of credits I ended up with was low, but on the other hand motivation was high all the time.

In our interpretation, the student was referring to the presence of internal motivation under a kind of flexibility that meant no external control. Yet another positive aspect is that despite the contradiction described, students commented that they needed to learn the skill of controlling their own work.

Student: I personally liked this flexibility a lot. Well, it was difficult to maintain a sufficient pace of working, but it was good practice for the future.

Negative comments $(5,16 \%)$, similar to negative fragments in the contradictory answers, highlight the difficulty of managing one's own schedule.

Student: I would prefer the way that people are required to work according to a schedule, i.e., after each week a certain number of exercises should be completed. It was now too easy to delay the work...

Student: It [the flexibility] hampered my working considerably, but this is fully due to the fact that I have never been good at studying things independently and scheduling my tasks...

As indicated by the quotes above, the student-proposed solutions for the difficulties they encountered are two-fold: one is the request for a more structured course, and the other is the need to improve on self-regulation. The latter portrays the course as a "practice round", as illustrated with yet another quote below.

Student: I could not keep up with my schedule, but this was my own fault. I could imagine that this form of learning is useful in the future.

5.3.3. Summary reflection. Flexibility was appreciated as an enabling element from the perspectives of scheduling the term and individual goal setting, and student comments on it referred to an experience of genuine learning orientation. The above-mentioned contradiction, which reveals students' difficulty in working without an external pull, described how these positive effects were reduced. A close inspection of the answers revealed the issue of low skill in and the need to improve self-regulation. Moreover, the data revealed that students might have, to some degree, accidentally forgotten to monitor their own progress, as there were requests for course-provided guidelines for being aware of progress (see "awareness of time management" in Section 5.1.2 and the quote in next section). From these premises, research on self-regulated learning (SRL), in particular whether SRL can be fostered by course arrangements, will draw our attention in the future. Research reviewed by Zimmerman [2008] promisingly suggests that both students' study processes and performance may be improved: A study by Schmitz and Wiese [2006] showed that college-aged students trained for SLR effectively achieved the goals they set for themselves, while a study by Stoeger and Ziegler 
[2008] showed that elementary school-aged students improved on their homework effectiveness, study managerial skills, and performance when teachers were trained for implementing SRL processes.

We also theorize that our efforts to develop the course are inevitably conditioned by students' perceptions and habits of studying in the present degree system, and that student adaptation to a flexible setting is difficult when there are particular "peak" courses in the curriculum clearly requiring self-regulation-cf. our interpretation of "practice round" above. There is a challenge of matching the micro level (single course development) and the macro level (how the course appears in the curriculum; system level). If observed at a macro level, based on the contradiction we found in the data, students seemed to be used to and expected "a governed need for learning" [Fejes 2006], although they liked the freedom provided.

The contradiction we saw in the data suggests that introducing flexibility was a failure. However, we noticed positive effects as to how we were able to support individual learning processes and study difficulties being referred to as personal improvable matters. Thus, we must not simply return to our previous FP1 setting but must specifically consider student learning in both micro and macro contexts and study what we can achieve by promoting self-regulation. Moreover, we noticed that this time (FP3) no student comments indicated "free riding" during the course. From this perspective, we think that we saw a baseline identifying student readiness to study a difficult topic under flexible conditions.

\subsection{Patterns from answers to Q10 ("Describe your motivation")}

On the positive side, students reported that they needed to know about functional programming in order to increase their value in the labor market. They also experienced the charm of novelty with functional programming/Haskell, and they valued the motivating atmosphere provided by the course personnel. Further, as noted earlier, students felt that they were attending this course for the sake of learning; hence, their comments were referring to internal motives.

On the negative side, student answers reveal a pattern showing that the difficulty of the topic, other pressures they were experiencing, and laziness led to delayed and fragmented study, which then decreased their motivation. The issues mentioned reflect well-known beginner difficulties, such as the type system-we have addressed this using exercises informed by cognitive load theory [Sweller et al. 1998] during our project [Tirronen and Isomöttönen 2015]. If we consider the data holistically, the flexibility of the course seems to relate to the attributes of laziness and other time pressures, which made it tempting to delay doing the work.

Student answer to Q8: At the very end of the course, my motivation decreased when I noticed that there was officially a week left, and a major part of the course was uncompleted.

The data from Q10 confirms the contradiction that emerged during FP3. The attribute of flexibility introduced severe self-management issues while removing the external pull. We observed that students sometimes referred to internal motivation. From the very beginning of our research project, we preferred to see genuine interest in the topic, reflected in informal learning, while the major challenge that emerged from FP3 is that we need to also achieve a result, as in the degree system.

\subsection{Analysis of study activity data}

In this section, by observing students' exercise returns on the semester timeline ("exercise distributions" from now on), our interest is to further our interpretation of the survey data, particularly regarding the attribute of flexibility, and discuss the pass rate. 
Table III. Exercise distribution information (average, standard deviation, and quartiles). There were 92 relevant submissions after excluding TAs' test cases, empty cases, and anonymous trials outside the semester. Activity time is described with two categories: $>3$ weeks and 1-3 weeks, while "subm" denotes the number of submissions.

\begin{tabular}{|c|c|c|c|c|c|c|c|}
\hline & \multicolumn{3}{|c|}{ Survey resp. (34) } & \multicolumn{3}{c|}{ Other identified (40) } & Unidentified (18) \\
\hline credits & $>0$ (pass) & 0 (dropped) & $>0$ (pass) & \multicolumn{2}{c|}{0 (dropped) } & 0 (dropped) \\
\hline activity weeks & all $>3$ & $>3$ & $1-3$ & all $>3$ & $>3$ & $1-3$ & all 1-3 \\
\hline n (students) & 26 & 5 & 3 & 5 & 13 & 22 & 18 \\
\hline subm.avg & 125.5 & 108.2 & 34.7 & 92.2 & 89.2 & 11.3 & 6.7 \\
\hline subm.stdev & 94.8 & 95.0 & 32.9 & 43.7 & 62.7 & 16.1 & 10.1 \\
\hline subm.min (Q0) & 24 & 45 & 10 & 32 & 12 & 1 & 1 \\
\hline subm.Q25\% & 68 & 55 & 16 & 80 & 47 & 3.25 & 1 \\
\hline subm.Q50\% & 91.5 & 62 & 22 & 91 & 66 & 5.5 & 3 \\
\hline subm.Q75\% & 148.5 & 106 & 47 & 105 & 130 & 10.75 & 5.75 \\
\hline subm.max (Q4) & 355 & 273 & 72 & 153 & 230 & 59 & 41 \\
\hline
\end{tabular}

We collected a total of 118 exercise distributions from our system, of which 92 were relevant and summarized in Table III. In calculating this course size, we excluded empty cases, TAs' test cases, and outside-semester trials in the submission system. The number 92 hence indicates students showing any submission activity during the semester and is based on the manual inspection of the study process data. Notice further that the activity category " $1-3$ weeks" in Table III counts students even with a single submission attempt. Students used acronyms when returning exercises, which enabled us to anonymously show the students' progress on the website. The correspondence between acronyms and real names was shown to the teacher when completing the course, at the latest. This procedure resulted in "unidentified" exercise distributions among 0 credit achievers, as shown in Table III. It is possible that a student used more than one acronym for submissions, which is why part of the unidentified distributions may be "complements" to other distributions. However, given the low study activity of this unidentified group, such partials would not contaminate, overall, our interpretations and characterizations below.

Before proceeding, we note that in all exercise distribution figures (Figures 6, 7, and 8) 'Accepted' indicates a sensible and working solution, 'Incorrect' indicates a wrongly implemented and/or erroneous solution, 'Missing' indicates that required elements are missing to the degree that review effort is not reasonable, and 'Discarded' indicates fully an out-of-scope submission. We included the categories 'Missing' and 'Discarded' as they also indicate a submission effort by the student and hence characterize study processes. The topmost distribution in Figure 6 presents an exercise distribution for the whole course population. Here, we find that students tended to spread their coursework over the flexible semester timeline. There is initial enthusiasm followed by decay. Then, along with passing the intended due date and by the beginning of the follow-up course, students seemed to be reactivated. Finally, there is a tail describing how the students finally completed the exercises. In this connection, we note that seven students took the course in the intended timeline with credits varying from 1 to 3 . Relatedly, there were also 5-credit achievers who did most of the exercises much before the intended due date and who returned to finish the last exercises after a notable amount of idle time and after the intended course due date. We conclude from the student comments that they selected to invest in another course they took in parallel with the elective functional programming course. In sum, the course seems passable in the intended timeline, while the flexible semester timeline was frequently exploited. Figure 6 also shows the overall distributions for 0-credit (fail) and 1-5-credit achievers 

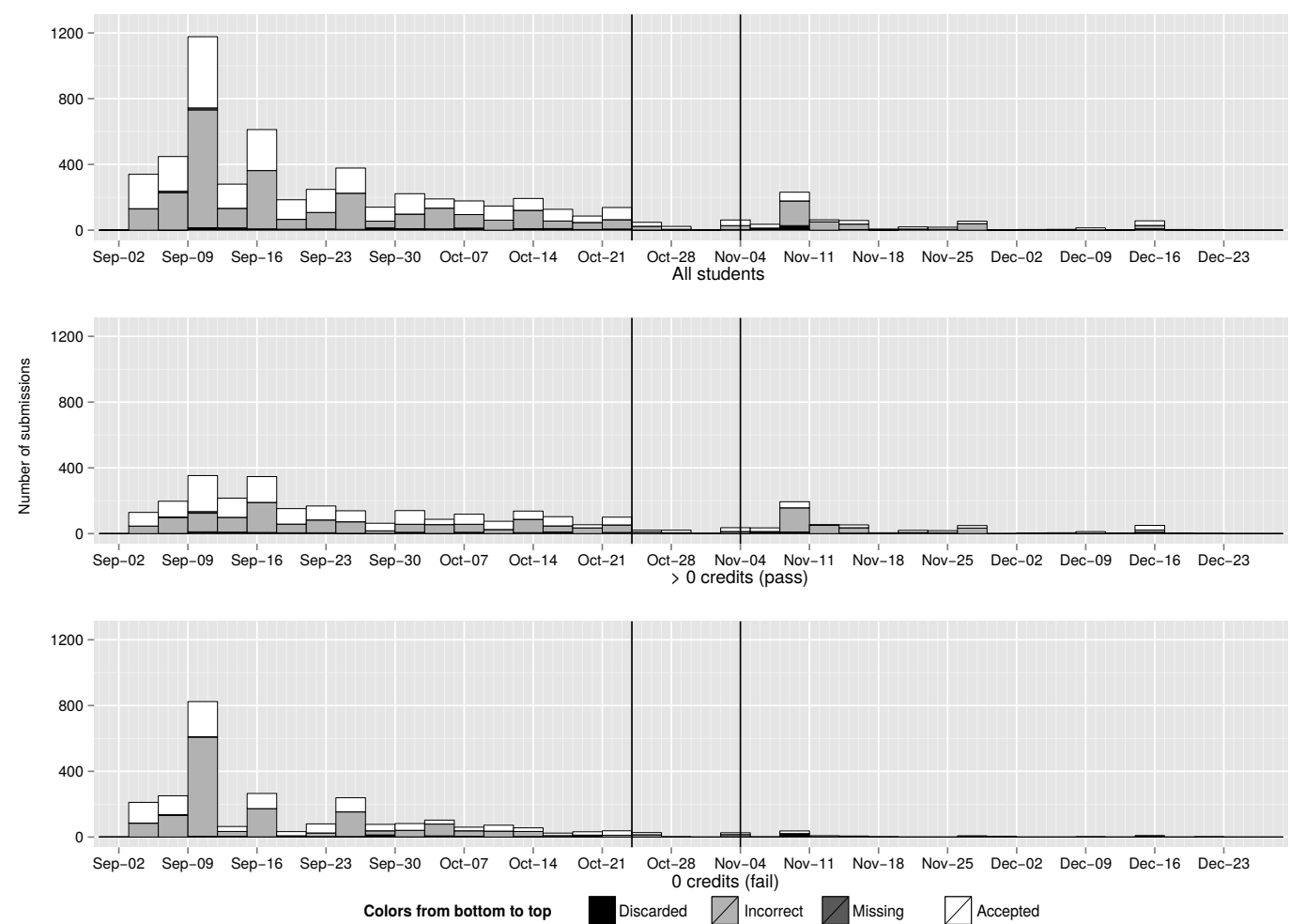

Fig. 6. The overall characterizations of study activity (top: all students, middle: $>0$ credits, bottom: 0 credits). In the distribution figures, the first vertical line shows the intended due date of the course, and the second shows the beginning of the follow-up course. Y-axis represents the number of submissions and X-axis time. Notice the order of gray-scale legends for valid interpretation.

(pass), which reveals that 0 -credit achievers show relatively more failed attempts with the exercises and a more decayed effort on the timeline.

Perhaps the most notable aspect in the distribution data is the high number of "tryouts". With this term, we refer to 430 -credit exercise distributions indicating activity only during 1-3 weeks. Table III also reveals low numbers of submissions for this group; see, in particular, the quartiles. Representative exercise distributions are given in Figure 7. The other group of 0-credit achievers describes an unfortunate category. These (18) students, with a more substantive effort on the timeline ( $>3$ weeks), also show more submissions, as observed using quartiles and average, the latter being not much less than that of passed students (see Table III).

All the students receiving one or more credits showed activity during more than three weeks. Representative cases of passed students' activity are given in Figure 8. Yet another important observation is that all the survey comments on flexibility harmonized with the corresponding exercise distributions. There were a couple of comments expressing "little" difficulties with the course when the corresponding exercise distributions indicated a considerably small effort, a kind of a "tryout" with the course-some over optimism could thus be interpreted.

In light of only 31 students receiving credits, the 118 exercise distributions initially counted from our system made us very worried about the course improvement-the first approximation of the pass rate was 31/92 (34\%) (see Table III). However, if we 

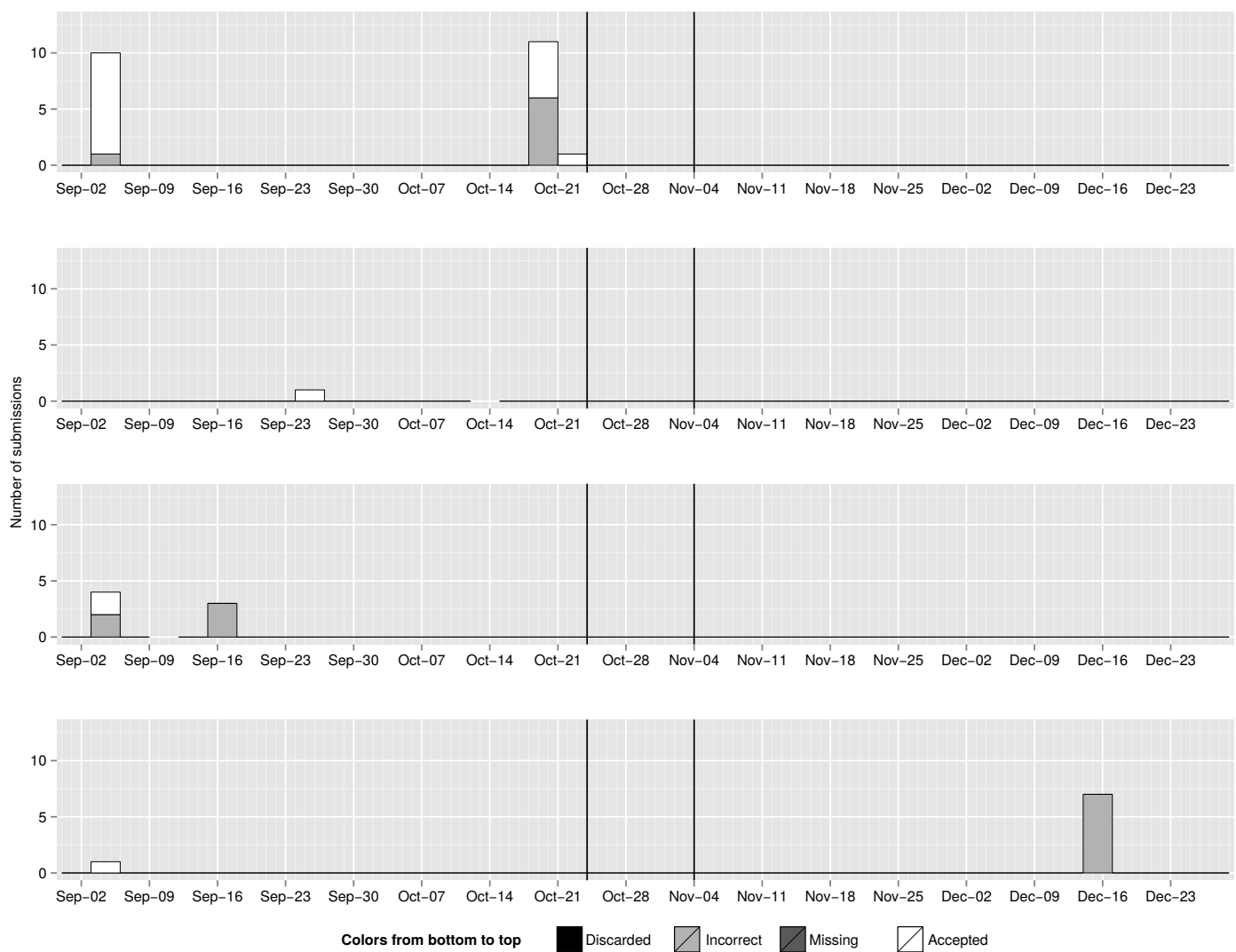

Fig. 7. Exemplary single-student cases of "tryouts." Y-axis represents the number of submissions and X-axis time. Notice the order of gray-scale legends for valid interpretation.

remove the tryouts and thus only count those who were active (returned exercises) during more than three weeks, we get a course population of 49 and pass rate of $63 \%$. For the FP1 course, we reported 35 passed students and a high increase in the pass rate. In this light, 31 students passing does not suggest a failure given the interpretation of little free riding and the high number of "tryouts".

The average number of credits for the 31 students was 3.1. The distribution of credits is given in Table IV. The table also shows a lot of variation in the number of submissions, and even within the credit categories. These variations likely explain the skill and schedule alignment issues with teacher-selected groups, even when based on the self-evaluation of skills requested from the students-our previous action research observation. If we look at 2-credit achievers who seem to show a high number of submissions, we cannot state simply one explanation for the numbers. The exercise distributions together with the qualitative data indicate that one student followed a set plan, another completed the course through intensive work in a short time period due to personal scheduling issues, while others found it challenging to continue for more credits due to self-regulation difficulty or the course topics. Altogether, the variations observed encourage the use of resizable groups and student-selected groups expressing spontaneous peer support. Furthermore, the second quartile (Q50\%) for 0-credit achievers being equal to 10, meaning that half the dropped students had no more than 10 submissions, supports our interpretation of the tryouts category. 

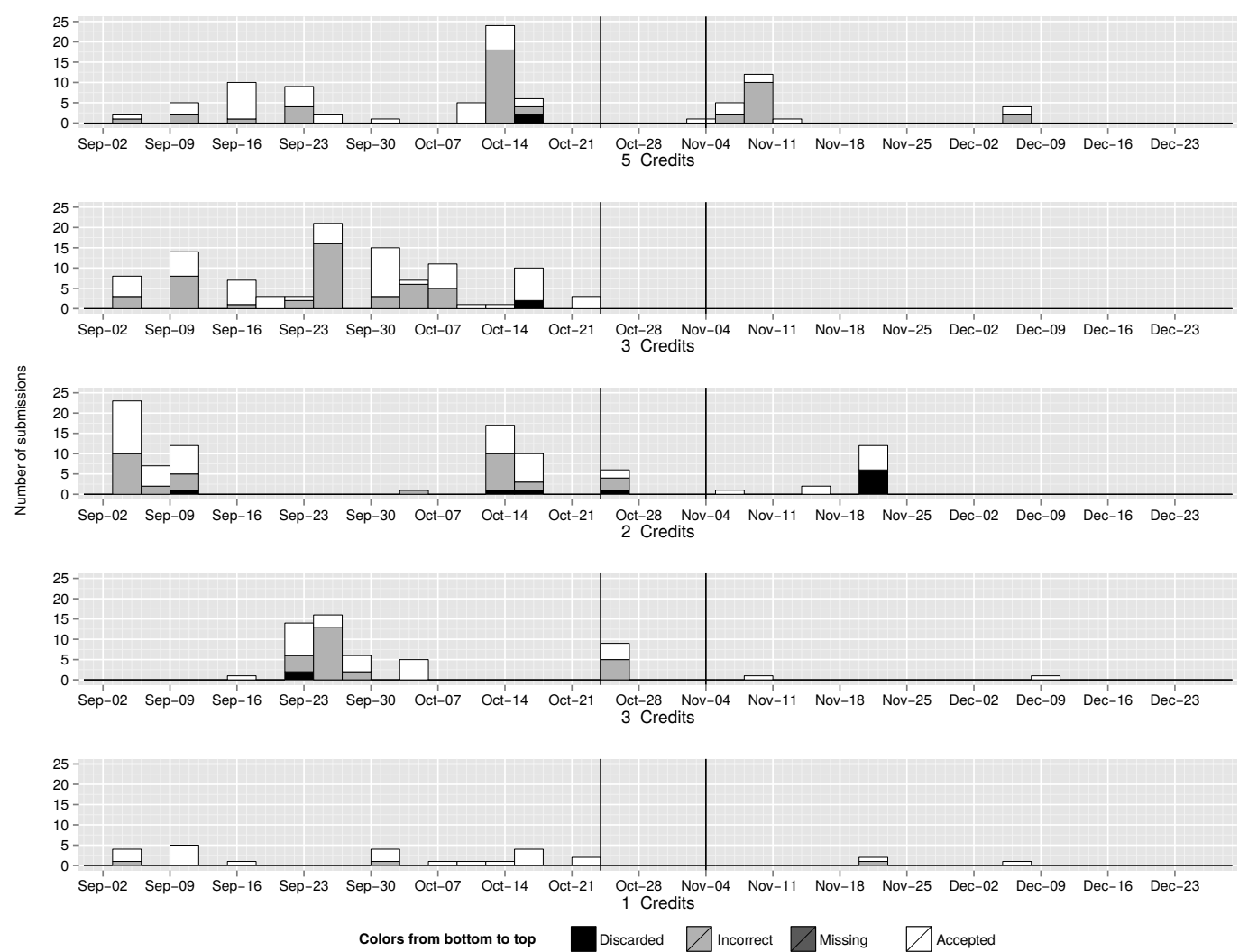

Fig. 8. Exemplary single-student cases of passed students. Y-axis represents the number of submissions and $\mathrm{X}$-axis time. Notice the order of gray-scale legends for valid interpretation.

Table IV. Submission information according to credit categories (average, standard deviation, and quartiles).

\begin{tabular}{ccccccccc}
\hline credits & $\mathrm{n}$ & subm.avg & subm.stdev & subm.min (Q0) & Q25\% & Q50\% & Q75\% & subm.max (Q4) \\
\hline 5 & 9 & 148.4 & 88.3 & 73 & 96 & 105 & 153 & 354 \\
4 & 3 & 185.3 & 109.7 & 122 & 122 & 122 & 217 & 312 \\
3 & 6 & 79.7 & 14.2 & 65 & 69.7 & 77.5 & 84.5 & 104 \\
2 & 7 & 158.7 & 106.9 & 56 & 79.5 & 144 & 198.5 & 355 \\
1 & 6 & 40.3 & 21.8 & 24 & 26 & 29 & 50.8 & 77 \\
0 & 61 & 35.7 & 55.4 & 1 & 3 & 10 & 53 & 273 \\
\hline
\end{tabular}

The observations on the exercise distributions increase our confidence regarding our interpretations of the survey data, particularly the contradiction that emerged from the flexible condition, on the one hand, and the positive echoes from student-selected resizable groups, on the other. We were also able to characterize the dropped course population and discuss the pass rate.

\section{DISCUSSION}

This article describes an action research project on programming education and presents the results of a third action research iteration, which focused on group work, flexibility, and learning resources as means of facilitating students' independent study. Figure 9 complements the FP3 study setting by summarizing the main reflections, 


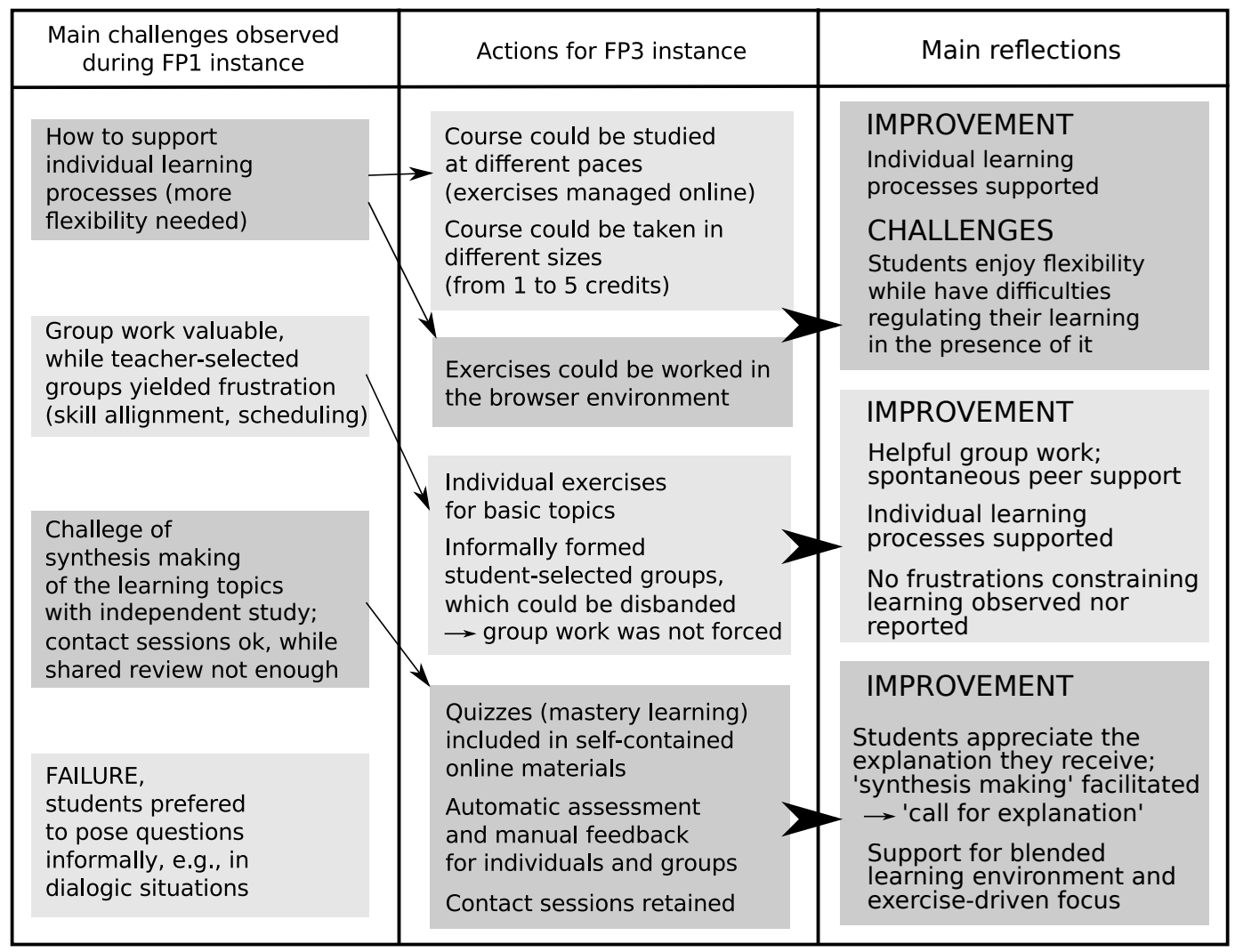

Fig. 9. Action research outcome. The right column complements the FP3 study setting with the main reflections; see Figure 3.

showing that improvement was specifically observed with the selected group work strategy and additions to the learning environment. As for the rigor of action research, the important improved control over the situation under study is the increased knowledge and awareness by which we are able to encounter forth-coming course populations purposefully.

The main challenge was the flexibility that was introduced to the course. It importantly contributed to individual learning processes, though for many it was a doubleedged sword. As for the concept of self-determination [Ryan and Deci 2000], students felt good about the flexibility as opposed to external control. However, their inability to "act upon" this feeling indicates the need for further actions. Bell et al. [2001] report on a similar effect regarding the students' use of video lectures. Their study indicates that students could not "follow their intentions," the authors rather strongly noting the damaging effect of flexible delivery. We might have taken too big a step in implementing flexibility with such a difficult course topic. Based on the proposed components of self-regulation - the forethought phase, performance phase, and self-reflection phase [Zimmerman and Campillo 2003] —we will integrate guidelines, self-reflective tasks, and feedback mechanisms into our online materials. The implementation of the forethought phase might benefit from learning agreements in which students clarify the key elements of forthcoming learning activities together with the stakeholders involved, as proposed by Clear [2010]. In our case, students agreeing on a study sched- 
ule and the number of credits (course size, learning goals) together with the teacher might make the self-regulation challenge explicit to students from the start. We will also specifically address particular course topics in particular review sessions, while the support sessions during the course weeks can address the variety of needs of students studying at different paces. This would give a basic rhythm to the course while retaining its flexible condition.

Moreover, we plan to contact all the students who dropped out and investigate whether their challenges were related to issues such as the known beginner difficulties in functional programming or the attribute of flexibility, or if they simply omitted finishing particular exercises in the setting resembling informal learning. The last item refers to an interesting perspective of dropping out. We might have witnessed an MOOC effect, where an increasing number of "tryouts" is inevitable due to the possibility of learning online, which would mean that we should be concerned with whether we introduced quality studying in absolute terms and whether the tryouts experienced important learning anyway; see discussion by Lakshminarayanan [2012]. Another explanation for the high number of tryouts may be the recency of functional programming.

When more students have completed this flexible course, we will investigate the relationship between self-regulation challenges and flexible credit compensation in detail. We speculate that self-regulation and other related challenges may link with how difficult or laborious the exercises are. An interesting research question is if the flexible (1-5) credit compensation causes students to consider, for instance, 2-credit work a "complete course", with the result that they desist form further efforts.

A study by Clear and Clear [2014] (in the New Zealand context) enables us to continue discussion from another perspective. These authors criticize a policy in which funding is based on quantitative performance indicators such as completion rates and note the tensions that follow. For instance, teachers, who want to deliver quality contents to learners, are pressurized by the expectations for increasingly high pass rates. In this respect, while we interpreted that the course promoted little free riding, it is clear that the high dropout rate will be noticed and regarded potentially unfavorably in the departmental context-one indicator currently determining funding in Finnish universities is the number of students who achieve the minimum of 55 ECTS credits per year. In agreement with thinking by Clear and Clear, we must not rashly water down the level of the course. We should keep in mind that students' response to flexibility included the positively stated need to practice self-regulation skills and widen the scope of our research.

Clear and Clear [2014] specifically discuss introductory programming, pointing out a mismatch between expectations of increasingly high pass rates and internationallyscoped studies showing roughly the same (constant) pass rate (about 67\%) (see [Watson and $\mathrm{Li} 2014]$ ). Based on the similar rates across several countries, Watson and $\mathrm{Li}$ [2014] conclude that reasons for student difficulties in introductory courses might be internal and that more work is needed to understand student behaviors. The present course is functional programming taught using Haskell and incorporates elements of distance learning, and not a first-year course. In this regard, comparing it to introductory programming is not straightforward. However, in our thinking, a transition from imperative to functional thinking makes the situation here a bit similar to introductory programming. Further, the self-regulation challenge stated by students accords with the conclusion by Watson and $\mathrm{Li}$ [2014], as it refers to students' behaviors. Accordingly, we argue that such research lines as retention and cognitive strategies in higher education should inform considerations on programming difficulties and pass rates, including the present efforts. The research on cognitive strategies has foregrounded study behavior characterizations such as self-handicapping, illusory optimism, and 
defensive pessimism (see a study by Heikkilä and Lonka [2006] and its references). Relatedly, Waite et al. [2004] have reported on procrastination as a factor constraining students' coursework.

As we suggest that the present research should be continued in a wider scope (macrolevel), we should also take into account that students' schooling background may constrain students' ability for self-directed studying (see discussion in [Henning 2012]), while yet another issue to consider is the present free university education potentially introducing "looseness" to study behaviors. By incorporating the issues and research lines discussed, our future actions can go beyond single-course didactics and exemplify critical action research.

\section{REFERENCES}

A. Amresh, A.R. Carberry, and J. Femiani. 2013. Evaluating the Effectiveness of Flipped Classrooms for Teaching CS1. In Frontiers in Education Conference. IEEE, 733-735. DOI : http://dx.doi.org/10.1109/FIE.2013.6684923

Jennifer Attride-Stirling. 2001. Thematic Networks: An Analytic Tool for Qualitative Research. Qualitative Research 1, 3 (2001), 385-405.

A. Bandura. 1986. Social foundations of thought and action: A social cognitive theory. Prentice Hall, Englewood Cliffs, NJ.

T. Bell, A. Cockburn, B. McKenzie, and J. Vargo. 2001. Flexible Delivery Damaging to Learning? Lessons From the Canterbury Digital Lectures Project. University of Canterbury. Computer Science and Software Engineering. http://ir.canterbury.ac.nz/handle/10092/517

K. Bijlani, S. Chatterjee, and S. Anand. 2013. Concept Maps for Learning in a Flipped Classroom. In Technology for Education (T4E), Fifth International Conference on. IEEE, 57-60. DOI : http://dx.doi.org/10.1109/T4E.2013.22

Benjamin S. Bloom. 1968. Learning for Mastery. Instruction and Curriculum. Regional Education Laboratory for the Carolina and Virginia, Topical Papers and Reprints, Number 1. Evaluation comment 1, 2 (1968), n2.

Phillip C. Candy. 1991. Self-Direction for Life-Long Learning: A Comprehensive Guide to Theory and Practice. Jossey-Bass, San Franscisco, CA.

Wilfred Carr and Stephen Kemmis. 1986. Becomming Critical: Education, Knowledge and Action Research. The Falmer Press, London.

Jennifer M. Case and Gregory Light. 2011. Emerging Methodologies in Engineering Education Research. Journal of Engineering Education 100, 1 (2011), 186-210.

Manuel M. T. Chakravarty and Gabriele Keller. 2004. The Risks and Benefits of Teaching Purely Functional Programming in First Year. Journal of Functional Programming 14, 1 (2004), 113-123.

Chris Clack and Colin Myers. 1995. The Dys-functional student. In Funtional Programming Languages in Education, Pieter Hartel and Rinus Plasmeijer (Eds.). Lecture Notes in Computer Science, Vol. 1022. Springer Berlin / Heidelberg, 289-309.

Alison Clear and Tony Clear. 2014. Introductory Programming and Educational Performance Indicators-A Mismatch. In Proceedings of ITX New Zealand's Conference of IT, M. Lopez and M. Verhaart (Eds.). CITRENZ, Hamilton, New Zealand, 123-128.

Tony Clear. 2004. Critical Enquiry in Computer Science Education. Taylor \& Francis, London, Chapter 2, 101-125.

Tony Clear. 2010. A Place for Learning Agreements in Capstone Computing Courses? ACM Inroads 1, 4 (2010), 10-11. DOI : http://dx.doi.org/10.1145/1869746.1869749

Catherine H. Crouch and Eric Mazur. 2001. Peer Instruction: Ten Years of Experience and Results. American Journal of Physics 69, 9 (2001), 970-977.

Katherine Cuthbert. 2001. Independent Study and Project Work: Continuities or Discontinuities. Teaching in Higher Education 6, 1 (2001), 69-84. doi:10.1080/13562510020029617.

Andreas Fejes. 2006. Constructing the Adult Learning: A Governmentality Analysis. Ph.D. Dissertation. Linköping Univeristy.

Jose Manuel Martins Ferreira. 2014. Flipped Classrooms: From Concept to Reality Using Google Apps. In Remote Engineering and Virtual Instrumentation (REV), 11th International Conference on. IEEE, 204208. DOI : http://dx.doi.org/10.1109/REV.2014.6784256 
Sally Fincher, Marian Petre, and Martyn Clark (Eds.). 2001. Computer Science Project Work: Principles and Pragmatics. Springer-Verlag, London.

J. H. Flavell. 1976. Metacognitive Aspects of Problem Solving. In The nature of Intelligence, L. B. Resnick (Ed.). Erlbaum, Hillsdale, NJ, 231-236.

Victor J. Friedman and Tim Rogers. 2009. There Is Nothing So Theoretical as Good Action Research. Action Research 7, 1 (2009), 31-47.

C. Furse. 2013. A Busy Professor's Guide to Sanely Flipping Your Classroom. In Antennas and Propagation Society International Symposium (APSURSI). IEEE, 2171-2172. DOI : http://dx.doi.org/10.1109/APS.2013.6711744

G.C. Gannod, J.E. Burge, and M.T. Helmick. 2008. Using the Inverted Classroom to Teach Software Engineering. In ICSE '08. ACM/IEEE 30th International Conference on. IEEE, 777-786. DOI : http://dx.doi.org/10.1145/1368088.1368198

Edward F. Gehringer and Barry W. Peddycord, III. 2013. The Inverted-lecture Model: A Case Study in Computer Architecture. In Proceeding of the 44th ACM Technical Symposium on Computer Science Education. ACM, New York, NY, 489-494. DOI : http://dx.doi.org/10.1145/2445196.2445343

Bill Genat. 2009. Building Emergent Situated Knowledges in Participatory Action Research. Action Research 7, 1 (2009), 101-115.

David George Glance, Martin Forsey, and Myles Riley. 2013. The pedagogical foundations of massive open online courses. First Monday 18, 5 (2013). DOI : http://dx.doi.org/10.5210/fm.v18i5.4350

B. G. Glaser. 1978. Theoretical Sensitivity: Advances in the Methodology of Grounded Theory. Sociology Press, San Francisco, CA.

Barney G. Glaser and Anselm L. Strauss. 1967. The Discovery of Grounded Theory: Strategies for Qualitative Research. Aldine de Gruyter, New York, NY.

Davydd J. Greenwood and Morten Levin. 1998. Introduction to Action Research. Social Research for Social Change. Sage Publications, Thousand Oaks, CA.

Gerald O. Grow. 1991. Teaching Learners to be Self-Directed. Adult Education Quarterly 41, 3 (1991), 125149.

S. Grundy. 1990. Three Models of Action Research. In The Action Research Reader (third ed.), S. Kemmis and R. McTaggart (Eds.). Deakin University Press, Geelong, 353-364. Reprinted from Grundy, S. (1982), Three Models of Action Research. Curriculum Perspectives, 2(3), 23-34.

Dianne Hagan, Sylvia Tucker, and Jason Ceddia. 1999. Industrial Experience Projects: A Balance of Process and Product. Computer Science Education 9, 3 (1999), 215 - 229.

Robert Harper. 2012. Practical Foundations for Programming Languages. Cambridge University Press, New York, NY.

Annamari Heikkilä and Kirsti Lonka. 2006. Studying in Higher Education: Students' Approaches to Learning, Self-Regulation, and Cognitive Strategies. Studies in Higher Education 31, 1 (2006), 99-117.

Hannu L. T. Heikkinen, Rauno Huttunen, and Leena Syrjälä. 2007. Action Research as Narrative: Five Principles for Validation. Educational Action Research 15, 1 (2007), 5-19. DOI : http://dx.doi.org/10.1080/09650790601150709

Teresa Henning. 2012. Writing Professor as Adult Learner: An Autoethnography of Online Professional Development. Journal of Asynchronous Learning Networks 16, 2 (2012), 9-26.

Kathryn Herr and Gary L. Anderson. 2005. The Action Research Dissertation: A Guide for Students and Faculty. Sage publications, Thousand Oaks, CA.

Ville Isomöttönen, Ville Tirronen, and Michael Cochez. 2013. Issues with a Course that Emphasizes Selfdirection. In Proceedings of the 18th ACM conference on Innovation and technology in computer science education (ITiCSE '13). ACM, New York, NY, 111-116. DOI : http://dx.doi.org/10.1145/2462476.2462495

Ville Isomöttönen and Ville Tirronen. 2013. Teaching Programming by Emphasizing Self-Direction: How Did Students React to Active Role Required of Them? Trans.Comput.Educ. 13, 2 (July 2013), 6:1-6:21.

S. Joosten, K. Berg, and G.V.D. Hoeven. 1993. Teaching functional programming to first-year students. Journal of Functional Programming 3, 1 (1993), 49-65.

S Lakshminarayanan. 2012. Ruminating about MOOCs. Journal of the NUS Teaching Academy 2, 5 (2012), 223-227.

Kurt Lewin. 1946. Action Research and Minority Problems. Journal of social Issues 2, 4 (Nov. 1946), 34-46.

SofieM.M. Loyens, Joshua Magda, and RemyM.J.P. Rikers. 2008. Self-Directed Learning in Problem-Based Learning and its Relationships with Self-Regulated Learning. Educational Psychology Review 20, 4 (2008), 411-427. DOI : http://dx.doi.org/10.1007/s10648-008-9082-7 
T. Lucke, U. Keyssner, and P. Dunn. 2013. The Use of a Classroom Response System to more Effectively Flip the Classroom. In Frontiers in Education Conference. IEEE, 491-495. DOI : http://dx.doi.org/10.1109/FIE.2013.6684872

Fred G. Martin. 2012. Will Massive Open Online Courses Change How We Teach? Sharing Recent Experiences With an Online Course. Commun. ACM 55, 8 (2012), 26-28.

Karl Maton and Rob Moore. 2010. Introduction: Coalitions of the Mind. Continuum, London, 1-13.

Mary J. Melrose. 2001. Maximazing the Rigor of Action Research: Why Would You Want To? How Could You? Field Methods 13, 2 (2001), 160-180.

Matthew B. Miles and A. Michael Huberman. 1984. Qualitative Data Analysis: A Sourcebook of New Methods. Sage, Beverly Hills, CA.

Michael Grahame Moore. 1973. Toward a Theory of Independent Learning and Teaching. Journal of Higher Education XLIV, 12 (1973), 661-679.

Rob Moore. 2000. For Knowledge: Tradition, Progressivism and Progress in Education-Reconstructing the Curriculum Debate. Cambridge Journal of Education 30, 1 (2000), 17-36.

Ben Moseley and Peter Marks. 2006. Out of the Tar Pit. Software Practice Advancement (SPA) (2006). http: //www.shaffner.us/cs/papers/tarpit.pdf

B.A. Oakley, D.M. Hanna, Z. Kuzmyn, and R.M. Felder. 2007. Best Practices Involving Teamwork in the Classroom: Results From a Survey of 6435 Engineering Student Respondents. Education, IEEE Transactions on 50, 3 (Aug. 2007), 266-272. DOI : http://dx.doi.org/10.1109/TE.2007.901982

Russell T. Osguthorpe and Charles R. Graham. 2003. Blended Learning Environments: Definitions and Directions. Quarterly Review of Distance Education 4, 3 (2003), 227-233.

Marian Petre and Mary Shaw. 2012. What's the Value Proposition of Distance Education? ACM Inroads 3, 3 (Sept. 2012), 26-28. DOI: http://dx.doi.org/10.1145/2339055.2339064

Latha Poonamallee. 2009. Building Grounded Theory in Action Research through the Interplay of Subjective Ontology and Objective Epistemology. Action Research 7, 1 (2009), 69-83.

Richard M. Ryan and Edward L. Deci. 2000. Self-Determination Theory and the Facilitation of Intrinsic Motivation, Social Development, and Well-Being. American Psychologist 55, 1 (2000), 68-78.

Bernhard Schmitz and Bettina S Wiese. 2006. New perspectives for the evaluation of training sessions in self-regulated learning: Time-series analyses of diary data. Contemporary educational psychology 31, 1 (2006), 64-96.

Heidrun Stoeger and Albert Ziegler. 2008. Evaluation of a classroom based training to improve selfregulation in time management tasks during homework activities with fourth graders. Metacognition and Learning 3, 3 (2008), 207-230. DOI : http://dx.doi.org/10.1007/s11409-008-9027-z

John Sweller, Jeroen J. G. van Merrienboer, and Fred G. W. C. Paas. 1998. Cognitive Architecture and Instructional Design. Educational Psychology Review 10, 3 (1998), 251-296.

Imogen Taylor and Hilary Burgess. 1995. Orientation to Self-directed Learning: Paradox or Paradigm? Studies in Higher Education 20, 1 (1995), 87-98.

Ville Tirronen and Ville Isomöttönen. 2012. On the Design of Effective Learning Materials for Supporting Self-directed Learning of Programming. In Proceedings of the 12th Koli Calling International Conference on Computing Education Research. ACM, New York, NY, 74-82. DOI : http://dx.doi.org/10.1145/2401796.2401805

Ville Tirronen and Ville Isomöttönen. 2015. Teaching types with a cognitively effective worked example format. Journal of Functional Programming 25, e23 (2015), 16 pages. DOI : http://dx.doi.org/10.1017/S0956796814000021

Ville Tirronen, Samuel Uusi-Mäkelä, and Ville Isomöttönen. 2015. Understanding beginners' mistakes with Haskell. Journal of Functional Programming 25, e11 (2015), 30 pages. DOI : http://dx.doi.org/10.1017/S0956796815000179

Marianne M. van den Hurk, Ineke H. A. P. Wolfhagen, Diana H. J. M. Dolmans, and Cees P. M. van der Vleuten. 1999. The Impact of Student-Generated Learning Issues on Individual Study Time and Academic Achievement. Medical Education 33 (1999), 808-814.

William M. Waite, Michele H. Jackson, Amer Diwan, and Paul M. Leonardi. 2004. Student Culture vs Group Work in Computer Science. SIGCSE Bull. 36, 1 (March 2004), 12-16. DOI : http://dx.doi.org/10.1145/1028174.971308

Christopher Watson and Frederick W.B. Li. 2014. Failure Rates in Introductory Programming Revisited. In Proceedings of the 2014 Conference on Innovation \& Technology in Computer Science Education (ITiCSE '14). ACM, New York, NY, 39-44. DOI : http://dx.doi.org/10.1145/2591708.2591749 
Barry J. Zimmerman. 2008. Investigating Self-Regulation and Motivation: Historical Background, Methodological Developments, and Future Prospects. American Educational Research Journal 45, 1 (2008), 166-183. http://dx.doi.org/10.3102/0002831207312909

B. J. Zimmerman and M. Campillo. 2003. Motivating Self-Regulated Problem Solvers. In The Nature of Problem Solving, J. E. Davidson and R. J. Sternberg (Eds.). Cambridge University Press, New York, 239.

Received February 2007; revised March 2009; accepted June 2009 